\title{
Mortality-related risk factors of COVID-19: a systematic review and meta-analysis of 42 studies and 423,117 patients
}

Zelalem G. Dessie ${ }^{1,2^{*}}$ and Temesgen Zewotir ${ }^{1}$

\begin{abstract}
Background: Mortality rates of coronavirus disease-2019 (COVID-19) continue to rise across the world. The impact of several risk factors on coronavirus mortality has been previously reported in several meta-analyses limited by small sample sizes. In this systematic review, we aimed to summarize available findings on the association between comorbidities, complications, smoking status, obesity, gender, age and D-dimer, and risk of mortality from COVID-19 using a large dataset from a number of studies.
\end{abstract}

Method: Electronic databases including Google Scholar, Cochrane Library, Web of Sciences (WOS), EMBASE, Medline/PubMed, COVID-19 Research Database, and Scopus, were systematically searched till 31 August 2020. We included all human studies regardless of language, publication date or region. Forty-two studies with a total of 423,117 patients met the inclusion criteria. To pool the estimate, a mixed-effect model was used. Moreover, publication bias and sensitivity analysis were evaluated.

Results: The findings of the included studies were consistent in stating the contribution of comorbidities, gender, age, smoking status, obesity, acute kidney injury, and D-dimer as a risk factor to increase the requirement for advanced medical care. The analysis results showed that the pooled prevalence of mortality among hospitalized patients with COVID-19 was 17.62\% (95\% Cl 14.26-21.57\%, 42 studies and 423,117 patients). Older age has shown increased risk of mortality due to coronavirus and the pooled odds ratio (pOR) and hazard ratio (pHR) were 2.61 (95\% $\mathrm{Cl} 1.75-3.47)$ and 1.31 (95\% Cl 1.11-1.51), respectively. A significant association were found between COVID-19 mortality and male $(\mathrm{pOR}=1.45 ; 95 \% \mathrm{Cl} 1.41-1.51 ; \mathrm{pHR}=1.24 ; 95 \% \mathrm{Cl} 1.07-1.41)$, and current smoker $(\mathrm{pOR}=1.42 ; 95 \% \mathrm{Cl}$ 1.01-1.83). Furthermore, risk of mortality among hospitalized COVID-19 patients is highly influenced by patients with Chronic Obstructive Pulmonary Disease (COPD), Cardiovascular Disease (CVD), diabetes, hypertension, obese, cancer, acute kidney injury and increase D-dimer.

Conclusion: Chronic comorbidities, complications, and demographic variables including acute kidney injury, COPD, diabetes, hypertension, CVD, cancer, increased D-dimer, male gender, older age, current smoker, and obesity are clinical risk factors for a fatal outcome associated with coronavirus. The findings could be used for disease's future research, control and prevention.

Keywords: Comorbidities, Demographic characteristics, Funnel plot, Heterogeneity, Publication bias, Sensitivity analysis

\footnotetext{
*Correspondence: DessieZ@ukzn.ac.za

${ }^{1}$ School of Mathematics, Statistics and Computer Science, University

of KwaZulu-Natal, Durban, South Africa

Full list of author information is available at the end of the article
} original author(s) and the source, provide a link to the Creative Commons licence, and indicate if changes were made. The images or other third party material in this article are included in the article's Creative Commons licence, unless indicated otherwise in a credit line to the material. If material is not included in the article's Creative Commons licence and your intended use is not permitted by statutory regulation or exceeds the permitted use, you will need to obtain permission directly from the copyright holder. To view a copy of this licence, visit http://creativecommons.org/licenses/by/4.0/. The Creative Commons Public Domain Dedication waiver (http://creativeco mmons.org/publicdomain/zero/1.0/) applies to the data made available in this article, unless otherwise stated in a credit line to the data. 

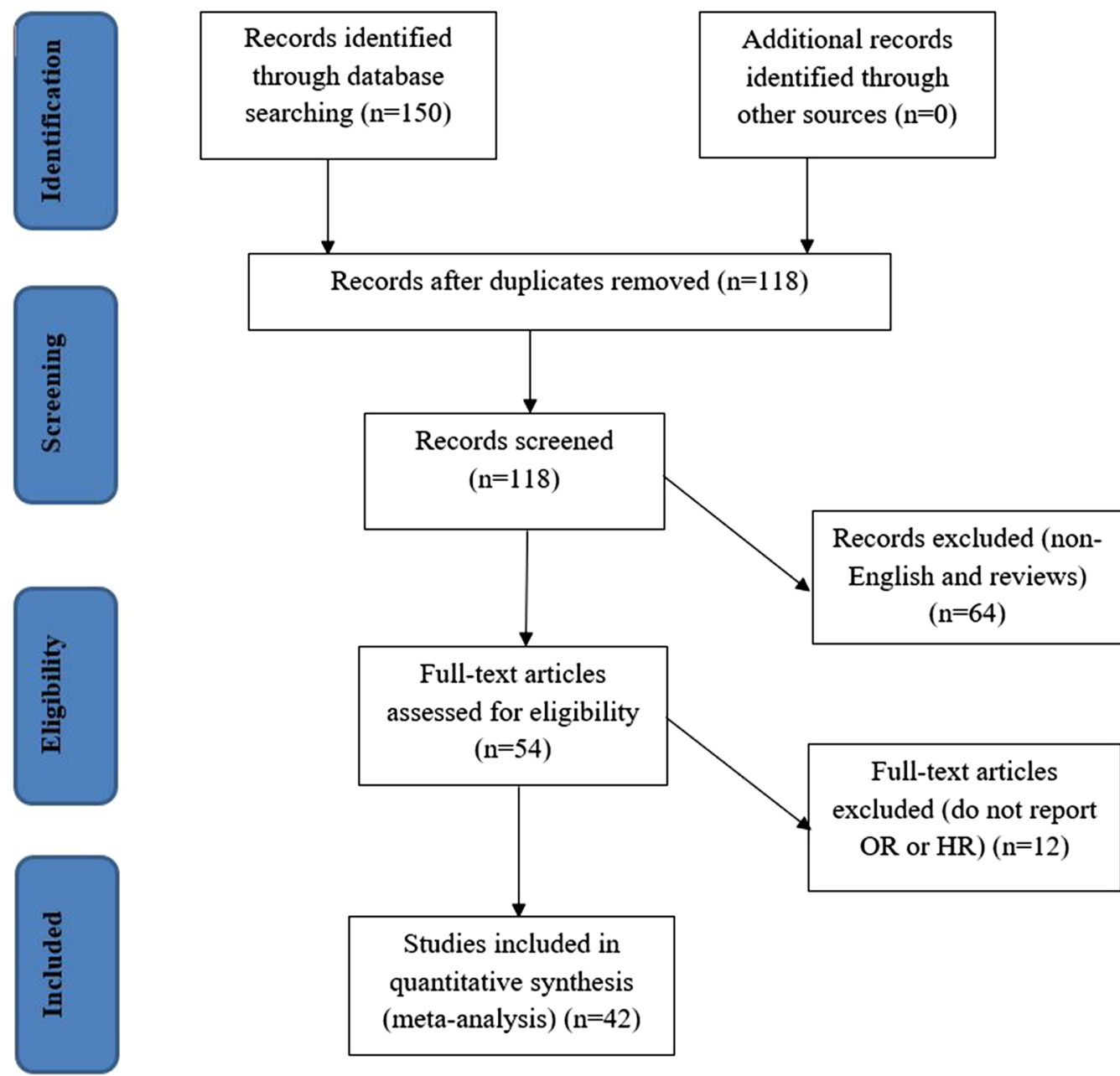

Full-text articles assessed for eligibility

Studies included in quantitative synthesis (meta-analysis) $(n=42)$

Fig. 1 Flow chart of the study search and screening process

\section{Introduction}

The 2019 novel coronavirus (2019-nCoV) is a newly emerging disease that was first reported in China, and has subsequently spread worldwide. COVID-19 is caused by severe acute respiratory syndrome coronavirus 2 (SARS-CoV-2), which belong to the family of Betacoronavirus genus [1]. Although the clinical presentation and symptoms of COVID-19 are similar to that of Middle East Respiratory Syndrome (MERS) and Severe Acute Respiratory Syndrome (SARS), the rate of spread is greater [2]. On 11 March 2019, the WHO defined COVID-19 as a pandemic disease [3], and as of February 2021, a total of 107,496,792 cases and 2,353,308 deaths (3.0\%) have been confirmed worldwide in 219 countries [4]. It is a major challenge for many countries to identify what measures could be used to avoid death or severe illness.
The challenge of COVID-19 is very high globally due to the complexity of its transmission and a lack of proven treatment $[5,6]$. It will be more disastrous for middle and low-income countries because of their high illiteracy, a very poor health care system, and a scarce Intensive Care Unit. A series of studies have reported clinical characteristics of COVID-19 critical illness [7] and severe illness [8] patients. The clinical features and risk factors considered aims for the identification of risk factors associated with fatal outcomes. Regardless of the scientist's effort to better understand the diagnostic, and clinical characteristics of the disease, our current understanding of patient's risk factors of death with COVID-19 is still limited. Accordingly one might not exhaustively study all possible risk factors. In every study, the considered risk factors vary in number and type. Based on the literature review we studied the commonly reported 


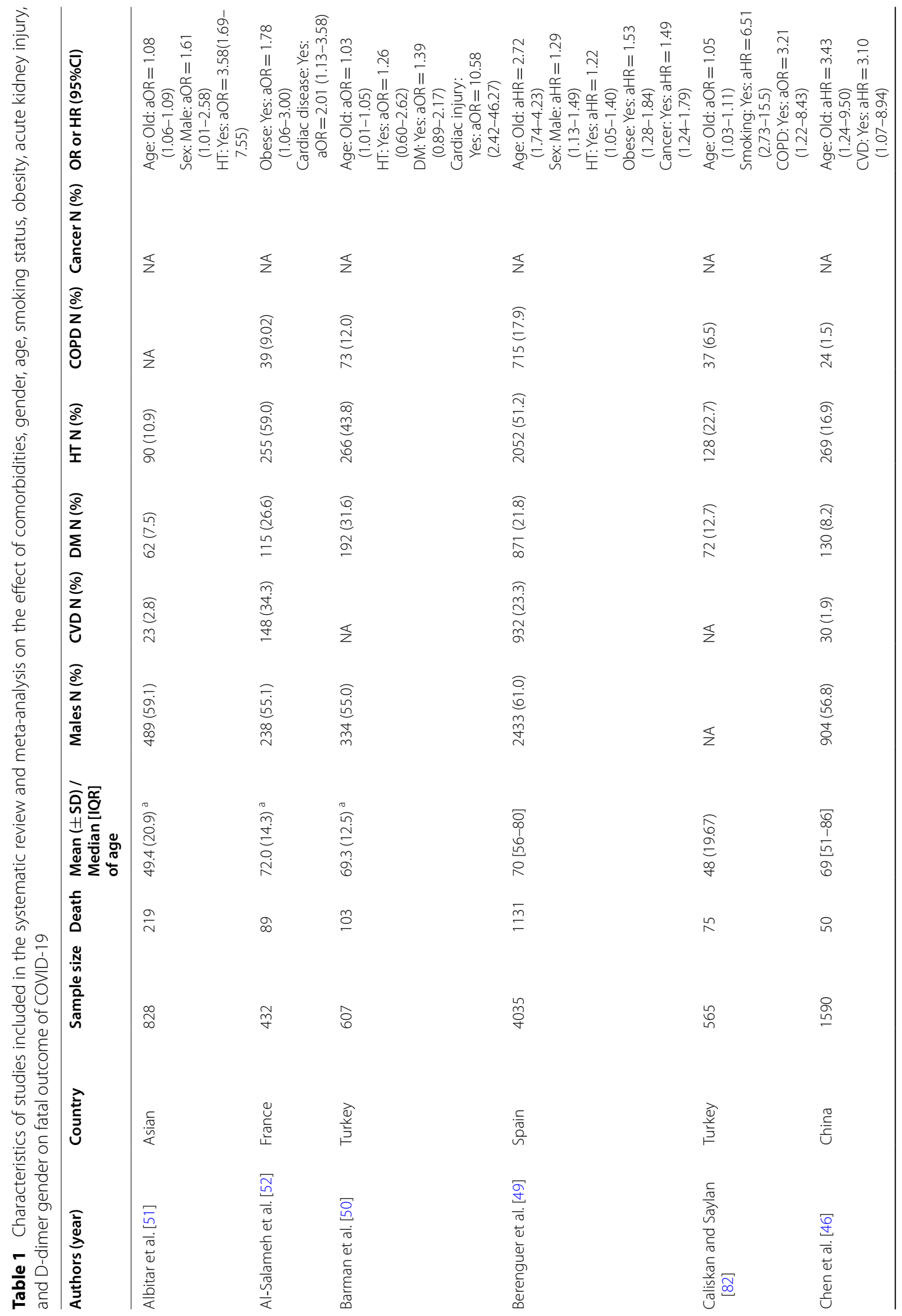




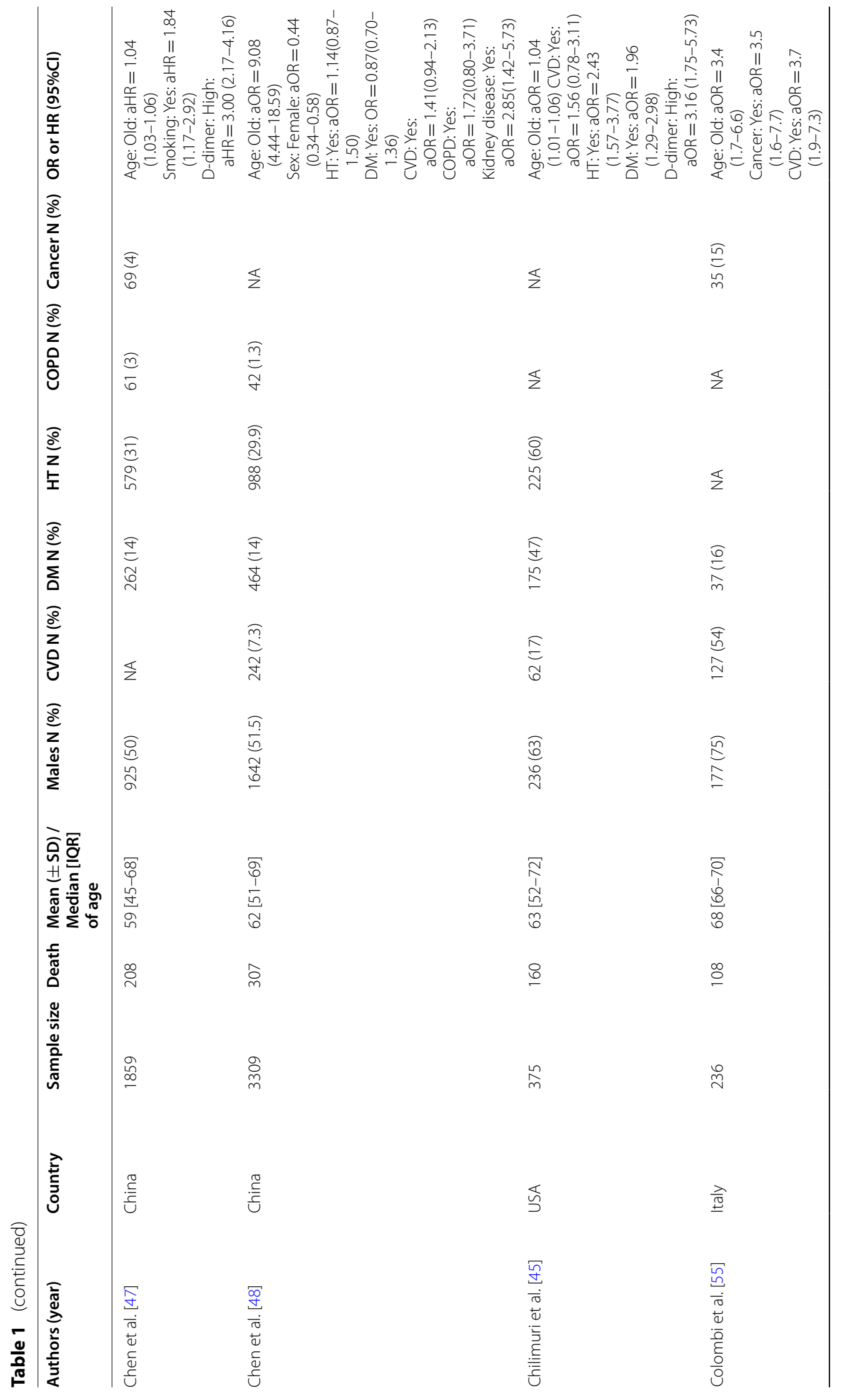




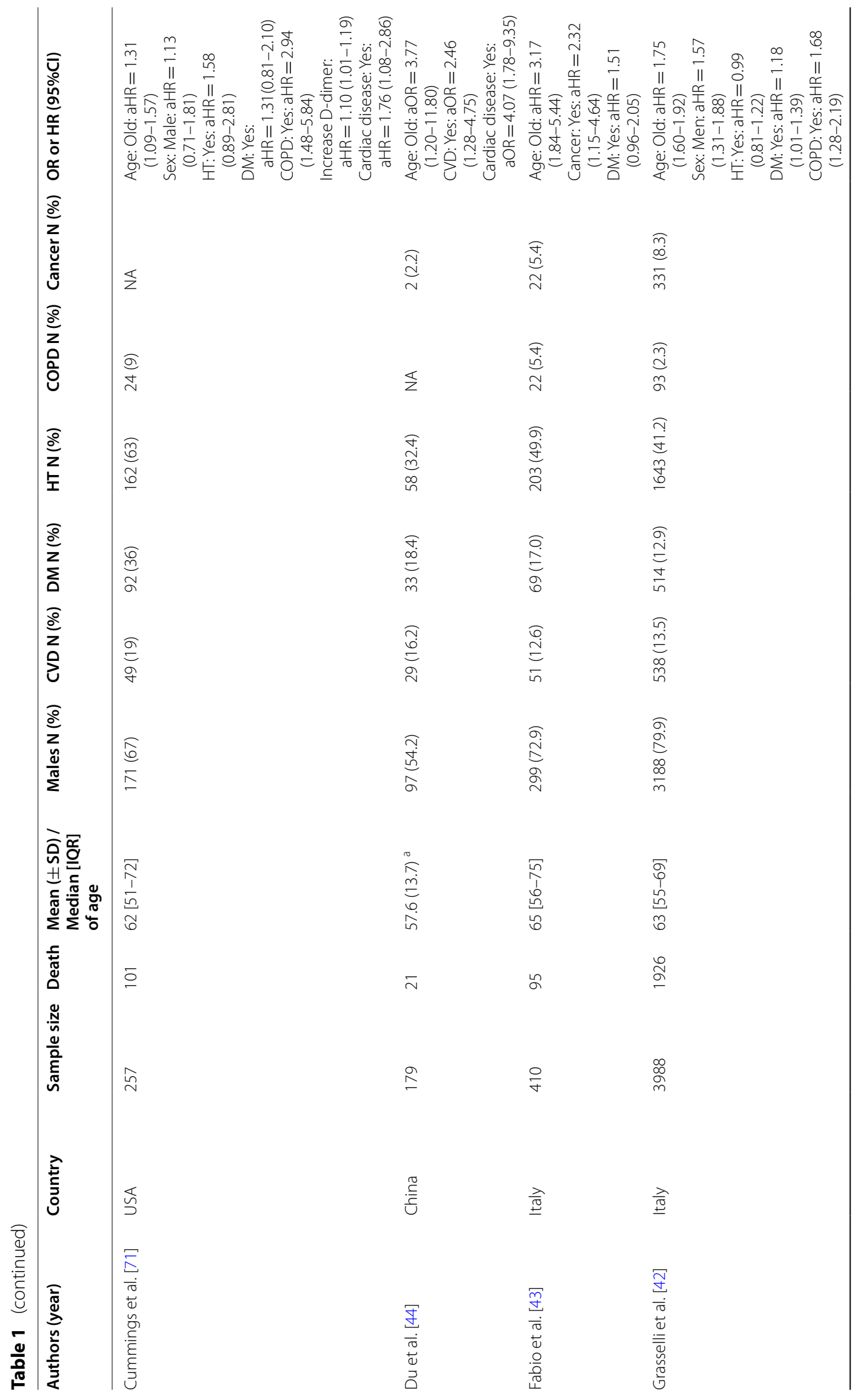




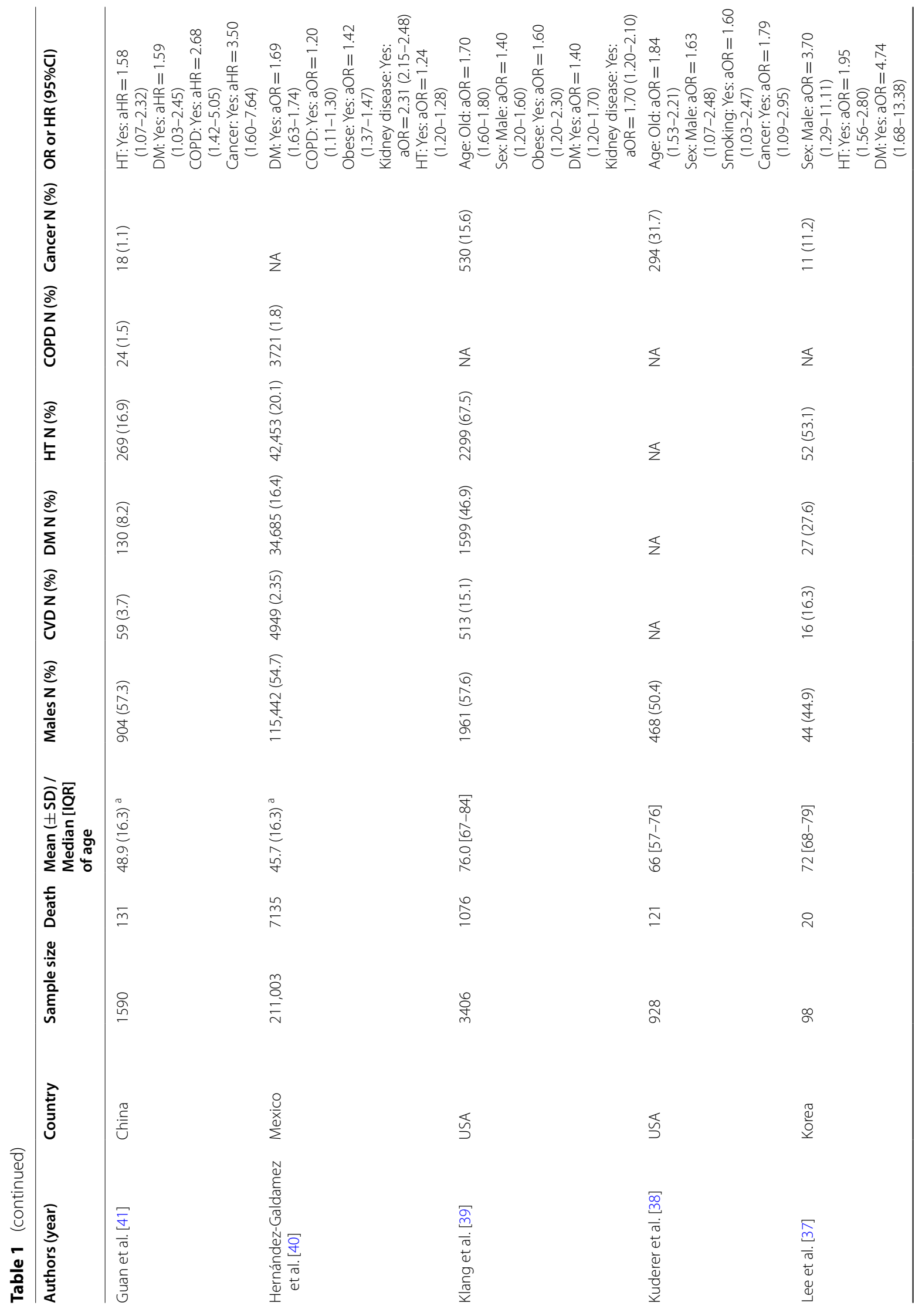


Dessie and Zewotir BMC Infect Dis $\quad$ (2021) 21:855

Page 7 of 28

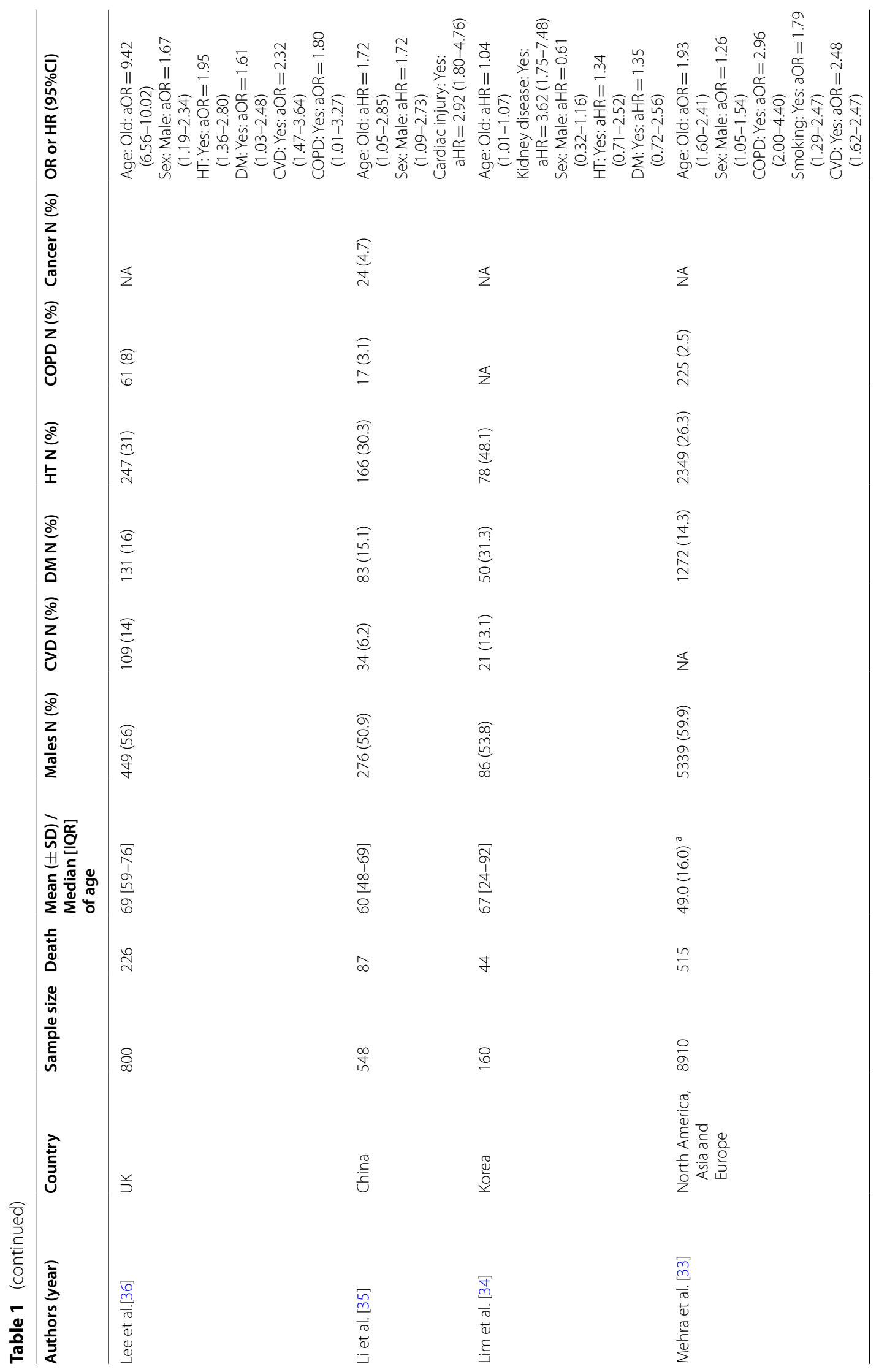




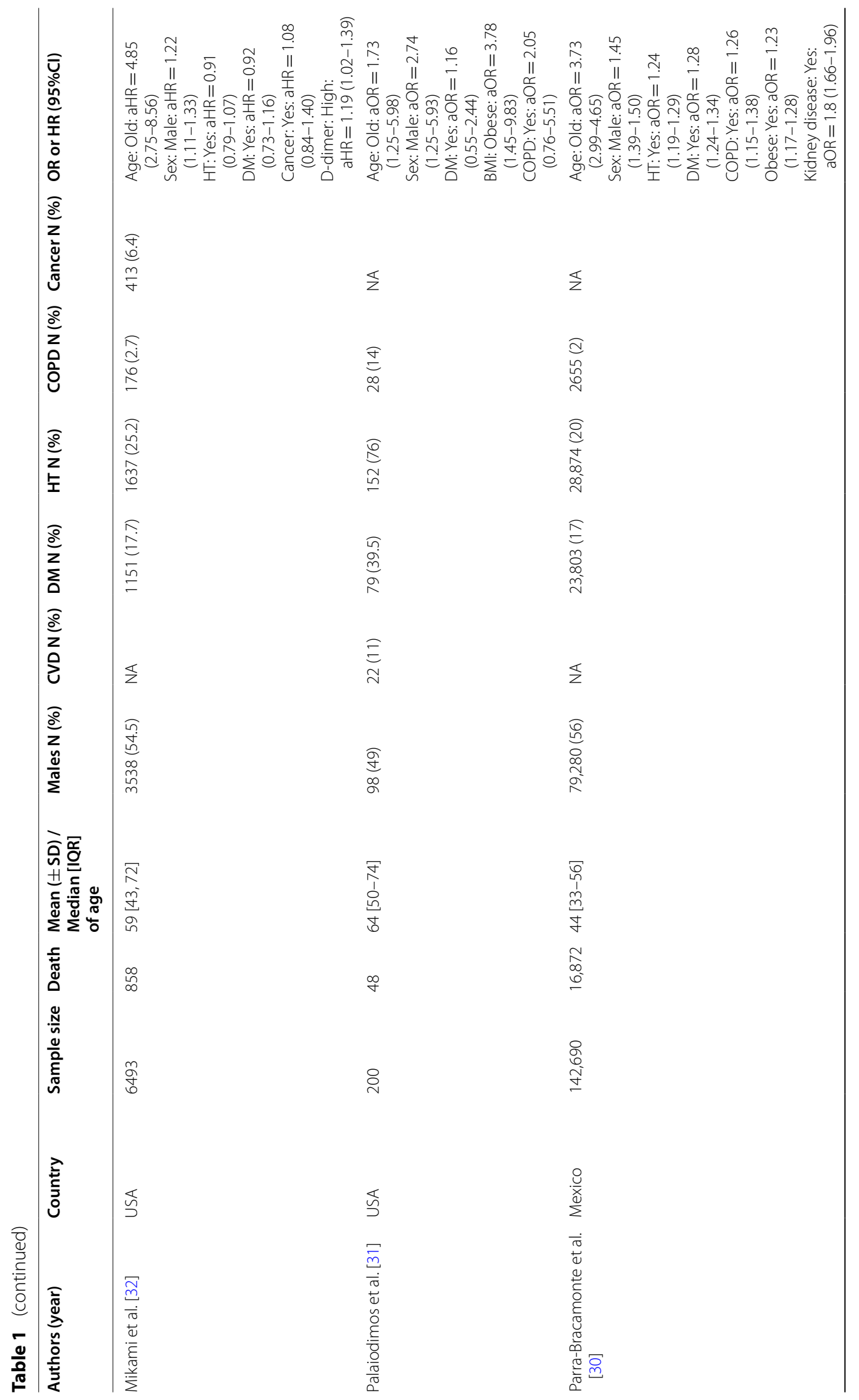




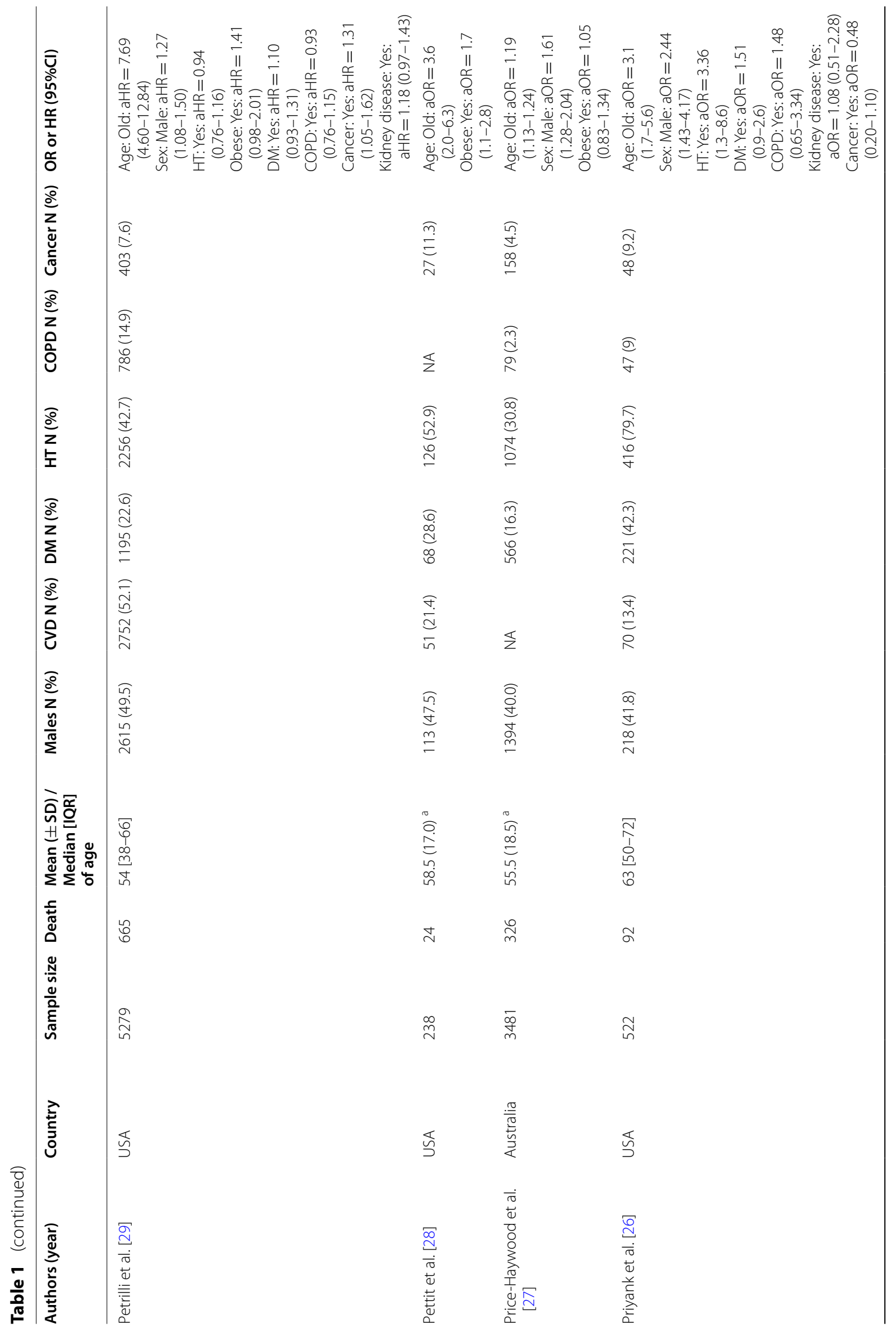




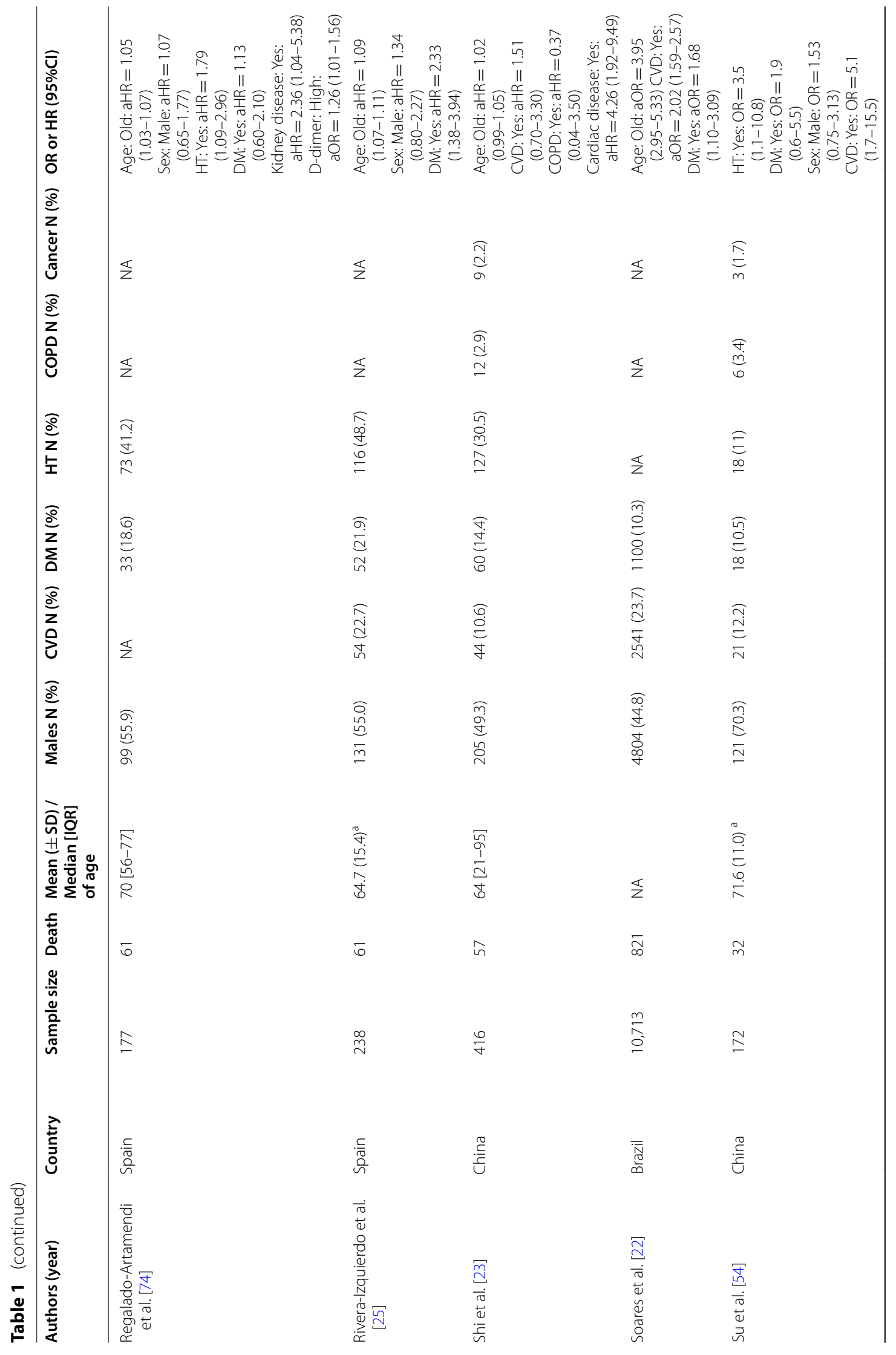




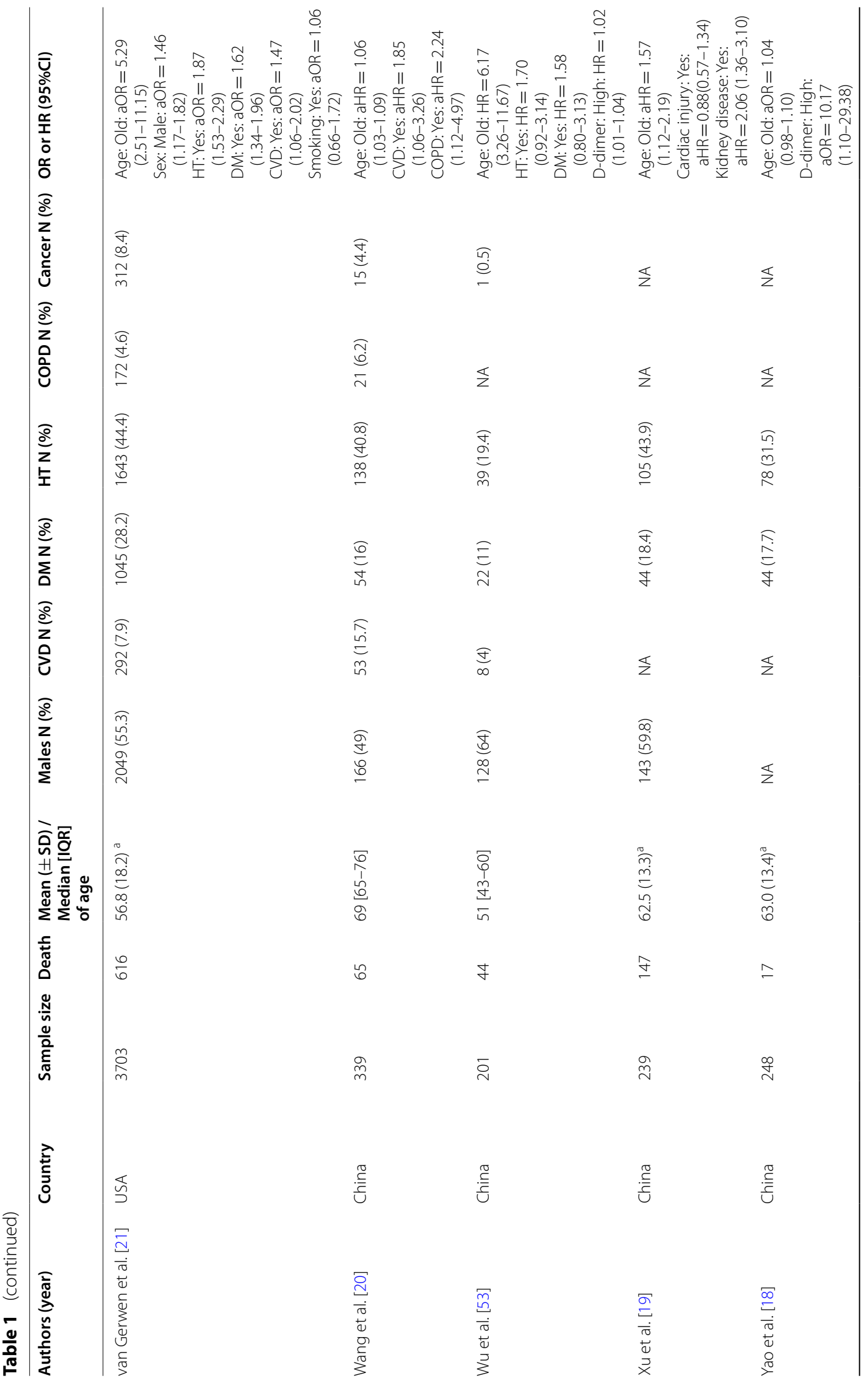




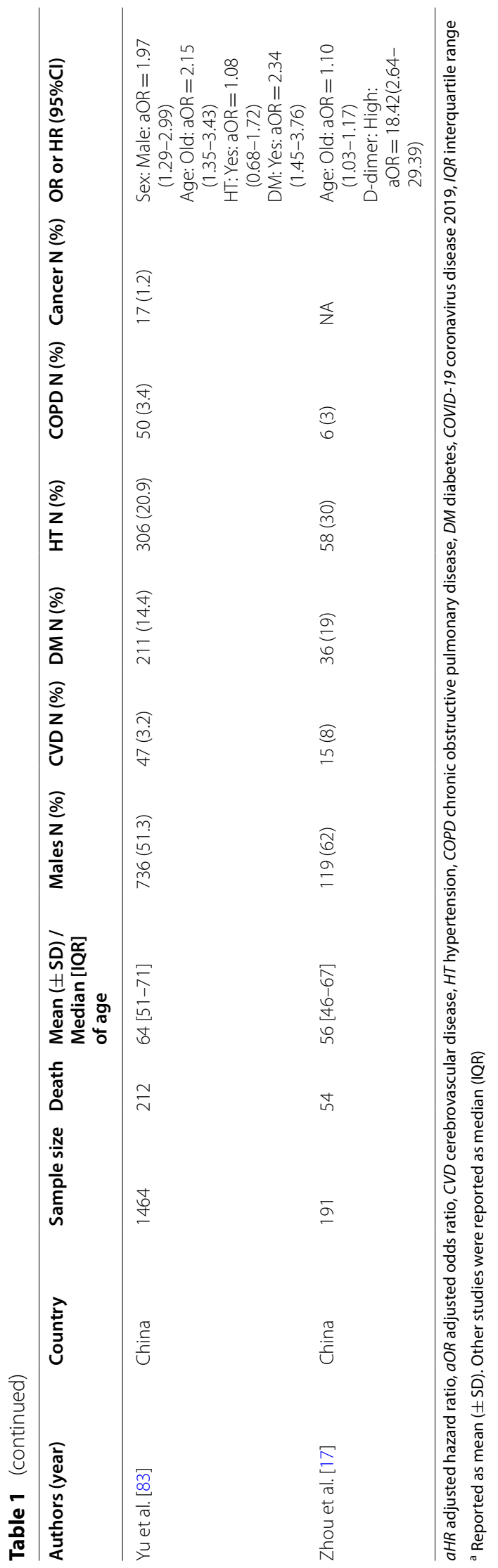


Study

Al-Salameh, et al. (2020)

Albitar, et al. (2020)

Barman, et al. (2020)

Berenguer, et al. (2020)

Caliskan and Saylan (2020)

Chen et al. (2020)

Chen, et al. (2020)

Chen, et al. (2020)

Chilimuri, et al. (2020)

Colombi et al. (2020)

Cummings et al. (2020)

Du, et al. (2020)

Fabio, et al. (2020)

Grasselli, et al. (2020)

Guan et al. (2020)

Hernández-Galdamez, et al.(2020)

Klang, et al.(2020)

Kuderer, et al. (2020)

Lee et al. (2020)

Lee et al.(2020)

$\mathrm{Li}$, et al. (2020)

Lim, et al. (2020)

Mehra, et al. (2020)

Mikami, et al. (2020)

Palaiodimos, et al. (2020)

Parra-Bracamonte, et al.(2020)

Petrilli, et al. (2020)

Pettit, et al. (2020)

Price-Haywood, et al. (2020)

Priyank, et al. (2020)

Regalado-Artamendi, et al. (2020)

Rivera-Izquierdo, et al. (2020)

Shi et al. (2020)

Soares, et al. (2020)

Su et al. (2020)

van Gerwen, et al. (2020)

Wang et al. (2020)

Wu et al. (2020)

$\mathrm{Xu}$, et al. (2020)

Yao, et al. (2020)

Yu, et al. (2020)

Zhou, et al. (2020)

Fixed effect model

Random effects model

Heterogeneity: $I^{2}=100 \%, \tau^{2}=0.6749, p=0$

\section{Events per 100}

observations

89

219

103

1131

75

50

208

307

160

108

101

21

95

1926

131

7135211003

1076

121

20

226

87

44

515

858

48

16872

665

$24 \quad 238$

$326 \quad 3481$

$92 \quad 522$

$61 \quad 177$

61238

$57 \quad 416$

$821 \quad 10713$

$32 \quad 172$

$616 \quad 3703$

65
339

$44 \quad 201$

147

17

212

54

423117
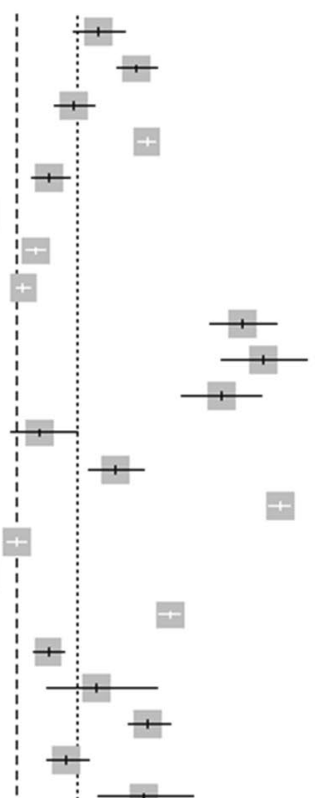

60

6493

200

00

79

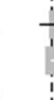

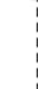

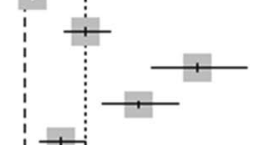

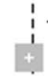

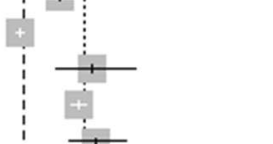

239

248

1464

191

\section{7}

$\frac{1}{\vdots}$

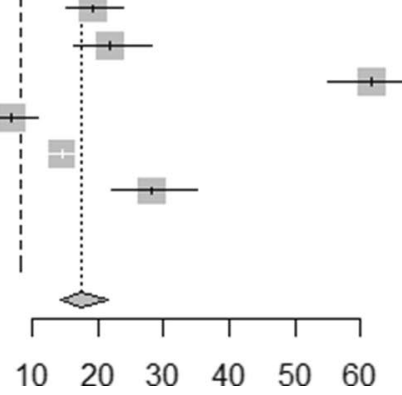

Events $\quad 95 \%-\mathrm{Cl}$

20.60 [16.88; 24.73]

26.45 [23.47; 29.59]

$16.97 \quad[14.07 ; 20.20]$

28.03 [26.65; 29.44]

13.27 [10.59; 16.35]

$3.14 \quad[2.34 ; 4.12]$

$11.19 \quad[9.79 ; 12.71]$

$9.28 \quad[8.31 ; 10.32]$

42.67 [37.60; 47.85]

$45.76 \quad[39.28 ; 52.35]$

39.30 [33.29; 45.56]

$11.73 \quad$ [ 7.41; 17.37]

$23.17[19.17 ; 27.56]$

48.29 [46.73; 49.86]

$8.24 \quad[6.93 ; 9.70]$

$3.38 \quad$ [3.30; 3.46]

$31.59[30.03 ; 33.18]$

13.04 [10.94; 15.38]

20.41 [12.93; 29.74]

28.25 [25.15; 31.51]

15.88 [12.92; 19.21]

27.50 [20.75; 35.11]

$5.78 \quad$ [5.30; 6.28]

$13.21[12.40 ; 14.06]$

24.00 [18.26; 30.53]

11.82 [11.66; 11.99]

$12.60[11.71 ; 13.52]$

$10.08 \quad[6.57 ; 14.63]$

$9.37 \quad[8.42 ; 10.38]$

$17.62[14.45 ; 21.17]$

34.46 [27.49; 41.96]

25.63 [20.21; 31.67]

$13.70 \quad[10.55 ; 17.39]$

$7.66 \quad$ [7.17; 8.18]

18.60 [13.09; 25.24]

$16.64[15.45 ; 17.87]$

19.17 [15.12; 23.77]

21.89 [16.38; 28.25]

$61.51[55.02 ; 67.71]$

$6.85 \quad[4.04 ; 10.75]$

14.48 [12.72; 16.39]

28.27 [22.01; 35.23]

8.28 [ 8.19; 8.36]

17.62 [14.26; 21.57]

Fig. 2 Forest plot showing the proportion of COVID-19 mortality

risk factors such as hypertension, diabetes, chronic obstructive pulmonary disease, dyspnoea, history of substance use, gender, acute respiratory distress syndrome (ARDS), history of smoking, older age, albumin, and D-dimer [9-12]. The study aims to synthesize and enhance our understanding about the precision of the risk factors effect on COVID-19 fatality rate. 
Table 2 Results of the subgroup analysis based on demographic and clinical variables associated with coronavirus mortality

\begin{tabular}{|c|c|c|c|c|c|c|c|}
\hline \multirow[t]{2}{*}{ Risk factors } & \multirow[t]{2}{*}{ Effect measures } & \multirow{2}{*}{$\begin{array}{l}\text { Numbers of } \\
\text { study }\end{array}$} & \multirow[t]{2}{*}{ Effect size $(95 \% \mathrm{Cl})$} & \multicolumn{2}{|c|}{ Heterogeneity } & \multirow{2}{*}{$\begin{array}{l}\text { Begg's test } \\
\text { P-value }^{\#}\end{array}$} & \multirow{2}{*}{$\begin{array}{l}\text { Egger's } \\
\text { test } \\
\text { P-value }\end{array}$} \\
\hline & & & & $1^{2}$ & P-value & & \\
\hline \multirow[t]{2}{*}{ Older age } & $\mathrm{pOR}$ & 21 & $2.61(1.75-3.47)$ & 99.97 & 0.000 & 0.321 & 0.531 \\
\hline & $\mathrm{pHR}$ & 16 & $1.31(1.11-1.51)$ & 99.54 & 0.000 & 0.212 & 0.142 \\
\hline \multirow[t]{2}{*}{ Gender: Male vs Female } & $\mathrm{pOR}$ & 15 & $1.45(1.41-1.51)$ & 66.63 & 0.000 & 0.243 & 0.213 \\
\hline & $\mathrm{pHR}$ & 9 & $1.24(1.07-1.41)$ & 62.45 & 0.000 & 0.424 & 0.126 \\
\hline \multirow[t]{2}{*}{ Smoking status: Yes vs No } & $\mathrm{pOR}$ & 5 & $1.42(1.01-1.83)$ & 55.81 & 0.000 & 0.143 & 0.076 \\
\hline & $\mathrm{pHR}$ & 1 & $1.84(0.96-2.71)$ & - & - & - & - \\
\hline \multirow[t]{2}{*}{ Obesity: Yes vs No } & $\mathrm{pOR}$ & 9 & $1.34(1.17-1.52)$ & 82.56 & 0.000 & 0.293 & 0.272 \\
\hline & $\mathrm{pHR}$ & 2 & $1.50(1.26-1.75)$ & 36.82 & 0.070 & 0.253 & 0.312 \\
\hline \multirow[t]{2}{*}{ CVDs: Yes vs No } & $\mathrm{pOR}$ & 9 & $1.83(1.50-2.17)$ & 41.27 & 0.020 & 0.410 & 0.388 \\
\hline & $\mathrm{pHR}$ & 3 & $1.77(0.95-2.59)$ & 13.73 & 0.160 & 0.426 & 0.143 \\
\hline \multirow[t]{2}{*}{ Diabetes } & $\mathrm{pOR}$ & 13 & $1.52(1.36-1.69)$ & 79.83 & 0.000 & 0.432 & 0.471 \\
\hline & $\mathrm{pHR}$ & 10 & $1.17(1.02-1.32)$ & 49.45 & 0.000 & 0.298 & 0.462 \\
\hline \multirow[t]{2}{*}{ Hypertension } & $\mathrm{pOR}$ & 12 & $1.57(1.27-1.87)$ & 94.97 & 0.000 & 0.114 & 0.399 \\
\hline & $\mathrm{pHR}$ & 8 & $1.18(1.01-1.40)$ & 66.66 & 0.000 & 0.054 & 0.267 \\
\hline \multirow[t]{2}{*}{ COPD } & $\mathrm{pOR}$ & 7 & $1.58(1.08-2.07)$ & 92.24 & 0.000 & 0.130 & 0.146 \\
\hline & $\mathrm{pHR}$ & 5 & $1.71(1.01-2.45)$ & 78.28 & 0.000 & 0.092 & 0.078 \\
\hline \multirow[t]{2}{*}{ Cancer } & $\mathrm{pOR}$ & 3 & $1.43(0.06-2.80)$ & 79.98 & 0.000 & 0.181 & 0.162 \\
\hline & $\mathrm{pHR}$ & 5 & $1.33(1.09-1.56)$ & 58.67 & 0.000 & 0.461 & 0.234 \\
\hline \multirow[t]{2}{*}{ Acute kidney injury } & $\mathrm{pOR}$ & 5 & $1.87(1.48-2.26)$ & 86.53 & 0.000 & 0.131 & 0.220 \\
\hline & $\mathrm{pHR}$ & 3 & $2.21(1.44-2.99)$ & 42.43 & 0.030 & 0.256 & 0.087 \\
\hline \multirow[t]{2}{*}{ Cardiac injury } & $\mathrm{pOR}$ & 3 & $2.33(0.88-3.79)$ & 5.97 & 0.320 & 0.088 & 0.090 \\
\hline & $\mathrm{pHR}$ & 4 & $1.89(0.75-3.02$ & 76.57 & 0.000 & 0.065 & 0.102 \\
\hline \multirow[t]{2}{*}{ Increased D-dimer } & $\mathrm{pOR}$ & 3 & $10.49(1.80-19.18)$ & 96.14 & 0.000 & 0.312 & 0.101 \\
\hline & $\mathrm{pHR}$ & 5 & $1.44(1.01-2.06)$ & 91.52 & 0.000 & 0.067 & 0.178 \\
\hline
\end{tabular}

Keys: (\#) $H_{0}$ there are no small study effects, $p O R$ pooled odds ratio, $p H R$ pooled hazard ratio

\section{Methods}

\section{Study protocol}

To examine the association between COVID-19 mortality versus in with comorbidities, gender, smoking status, obesity, age, acute kidney injury, and D-dimer, we followed PRISMA guidelines [13] to perform the meta-analysis of the articles identified through our systematic reviews.

\section{Search strategy}

Electronic databases including Google Scholar, Cochrane Library, Web of Sciences (WOS), EMBASE, Medline/PubMed, COVID-19 Research Database (WHO), COVID-19 Open Research Dataset Challenge, and Scopus, were systematically searched till 31 August 2020. The search strategy was as follows: ("severe acute respiratory syndrome coronavirus 2" or "novel coronavirus" or "COVID-19" or "2019-nCoV" or "SARS-CoV-2") and ("survival" or "fatal outcome" or "mortality" or "death"). Furthermore, the search was specifically focused on articles that analyzed laboratory parameters, pre-existing comorbidities, clinical status, and demographic characteristics as potential predictors for fatal outcome of COVID-19. No restriction was applied on time and language of publications. In order to improve the screening process and save time, we downloaded the literature results into EndNote X9.

\section{Eligibility criteria}

Once duplicates were removed, the initial search results were screened for relevance by titles and abstracts by both authors. The full texts were reviewed for the eligibility criteria (Fig. 1). Studies without abstract and/ or full text, Correspondence letters, COVID-19 studies on children only, editorials, reviews, qualitative studies, books, theses, expert opinion papers, and review articles were excluded from the analysis. Furthermore, among the eligible studies, we used if only the study reported odds ratios (ORs) or hazard ratios (HRs) along with 95\% $\mathrm{CI}$ for the association between demographic or epidemiological or clinical characteristics and fatal outcome of coronavirus. 


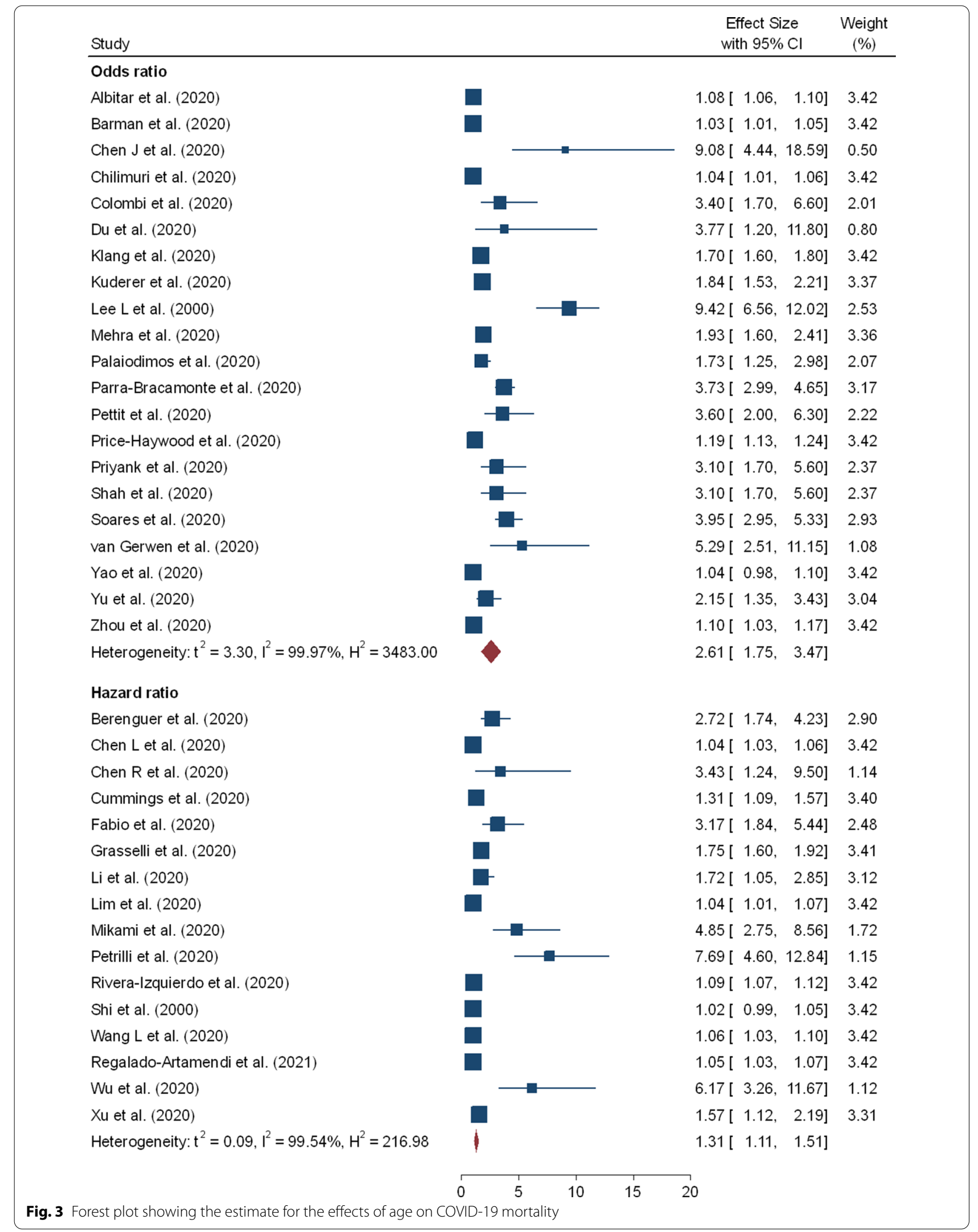




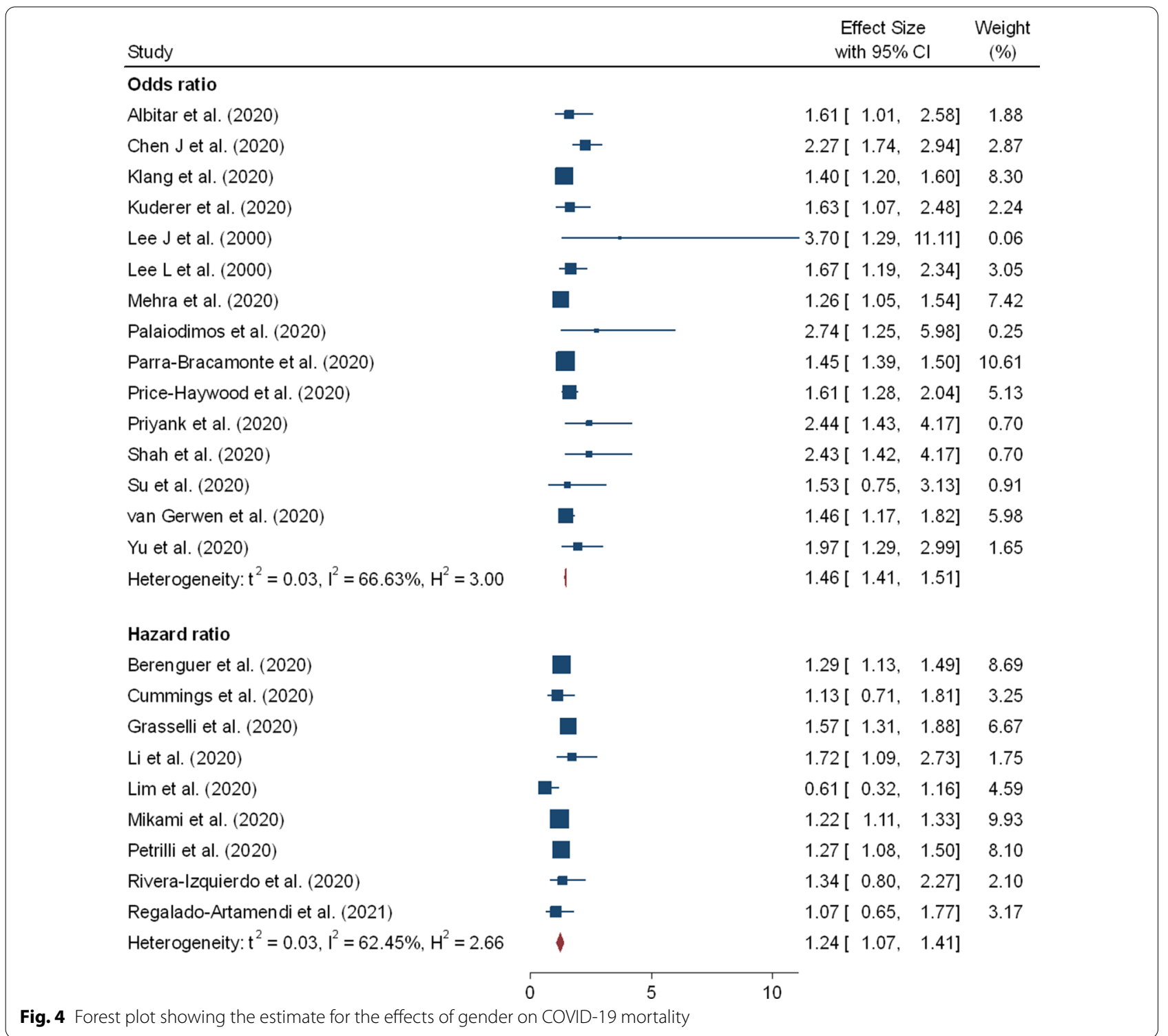

\section{Data extraction and assessment for study quality}

Both authors independently examined the downloaded EndNote X9 search outputs eligibility for inclusion. Any disagreements between the authors were resolved through discussion and mutual agreement. Both authors extracted the following data: the first author's name, countries, assessment methods, sample size, study design, the publication year, demographic variables (e.g., gender, age, etc.), clinical variables (e.g., comorbidities, complications, D-dimer, etc.), outcome (mortality), exposure (risk factors), and adjusted odds ratios or hazard ratios or relative risk. The authors independently evaluated the quality methodological approach of the articles using a Newcastle-Ottawa technique [14]. In this technique, three main components were utilized to assess the quality of the papers such as assessment of the outcome, comparability of the study groups, and selection procedure of the study patients. The Newcastle-Ottawa technique included seven domains, each one of these domains were scored from 3 to 0 (i.e., from low to high bias) and their average score were taken.

\section{Statistical analysis}

We have used peer-reviewed and published ORs or HRs (and their 95\%CI) for the association between the fatal outcome of COVID-19 and risk factors. A mixed-effect 


\section{A) Obese: Yes vs No}

Study

Effect Size

Weight

Odds ratio

Al-Salameh et al. (2020)

Hernández-Galdamez et al. (2020)

Klang et al. (2020)

Palaiodimos et al. (2020)

Parra-Bracamonte et al. (2020)

Pettit et al. (2020)

Price-Haywood et al. (2020)

Priyank et al. (2020)

Shah et al. (2020)

Heterogeneity: $\mathrm{t}^{2}=0.03, \mathrm{I}^{2}=82.56 \%, \mathrm{H}^{2}=5.73$

with $95 \% \mathrm{Cl}$

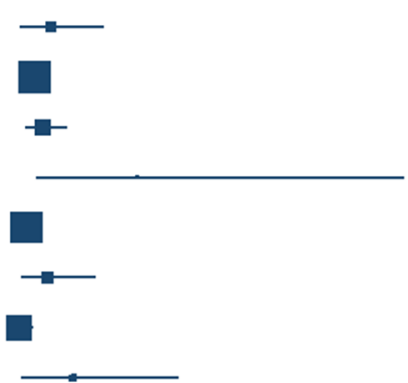

$1.78[1.06,3.00] 2.21$

1.42 [ $1.37,1.47] 26.09$

$1.60[1.20,2.30] \quad 5.86$

3.78 [ $1.45,9.83] \quad 0.13$

1.23 [ $1.17,1.28] 25.93$

$1.70[1.10,2.80] 2.81$

$1.05[0.83,1.34] 15.17$

2.29 [ $1.11,4.69] \quad 0.69$

2.29 [ $1.11,4.69] \quad 0.69$

1.34 [ $1.17,1.52]$

\section{Hazard ratio}

Berenguer et al. (2020)

Petrilli et al. (2020)

Heterogeneity: $\mathrm{t}^{2}=0.08, \mathrm{I}^{2}=36.82 \%, \mathrm{H}^{2}=1.58$

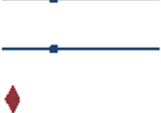

\begin{tabular}{l|l}
\hline 0 & 10
\end{tabular}

B) Smoking status: Yes vs No

\begin{tabular}{|c|c|c|}
\hline Study & $\begin{array}{c}\text { Effect Size } \\
\text { with } 95 \% \mathrm{Cl}\end{array}$ & $\begin{array}{c}\text { Weight } \\
(\%)\end{array}$ \\
\hline \multicolumn{3}{|l|}{ Odds ratio } \\
\hline Kuderer et al. (2020) & $1.60[1.03$ & 17.95 \\
\hline Mehra et al. (2020) & $1.79[1.29,2.47]$ & 23.01 \\
\hline Shah et al. (2020) & $1.03[0.55$ & 18.63 \\
\hline van Gerwen et al. (2020) & $1.06[0.66,1.72]$ & 25.90 \\
\hline Caliskan and Saylan (2020) & $-6.51[2.73,10.50]$ & 0.90 \\
\hline Heterogeneity: $\mathrm{t}^{2}=0.18, \mathrm{I}^{2}=55.81 \%, \mathrm{H}^{2}=2.26$ & $1.42[1.01,1.83]$ & \\
\hline \multicolumn{3}{|l|}{ Hazard ratio } \\
\hline Chen L et al. (2020) & $1.84[1.17$ & 13.60 \\
\hline Heterogeneity: $\mathrm{t}^{2}=0.00, \mathrm{I}^{2}=. \%, \mathrm{H}^{2}=$. & $1.84[0.96$ & \\
\hline
\end{tabular}

Fig. 5 Forest plot showing the estimate for the effects of smoking status and obesity on COVID-19 mortality

model has been computed keeping into consideration the expected between-study heterogeneity. Heterogeneity in effect sizes was assessed by computing Cochran's $Q$ test; a significant $Q$ indicates a lack of homogeneity and inference of heterogeneity. The proportion of the total variance attributable to the study heterogeneity was determined using $I^{2}$ statistic [15]. The $I^{2}$ values of 60-90\%, 40-59\%, and 0-39\% were considered to indicate severe, moderate, and mild, respectively [15]. Funnel plots with Egger weighted regression test were used for assessing publication bias [16]. All of the analyses were implemented with the statistical software's R-4.0.2 and 


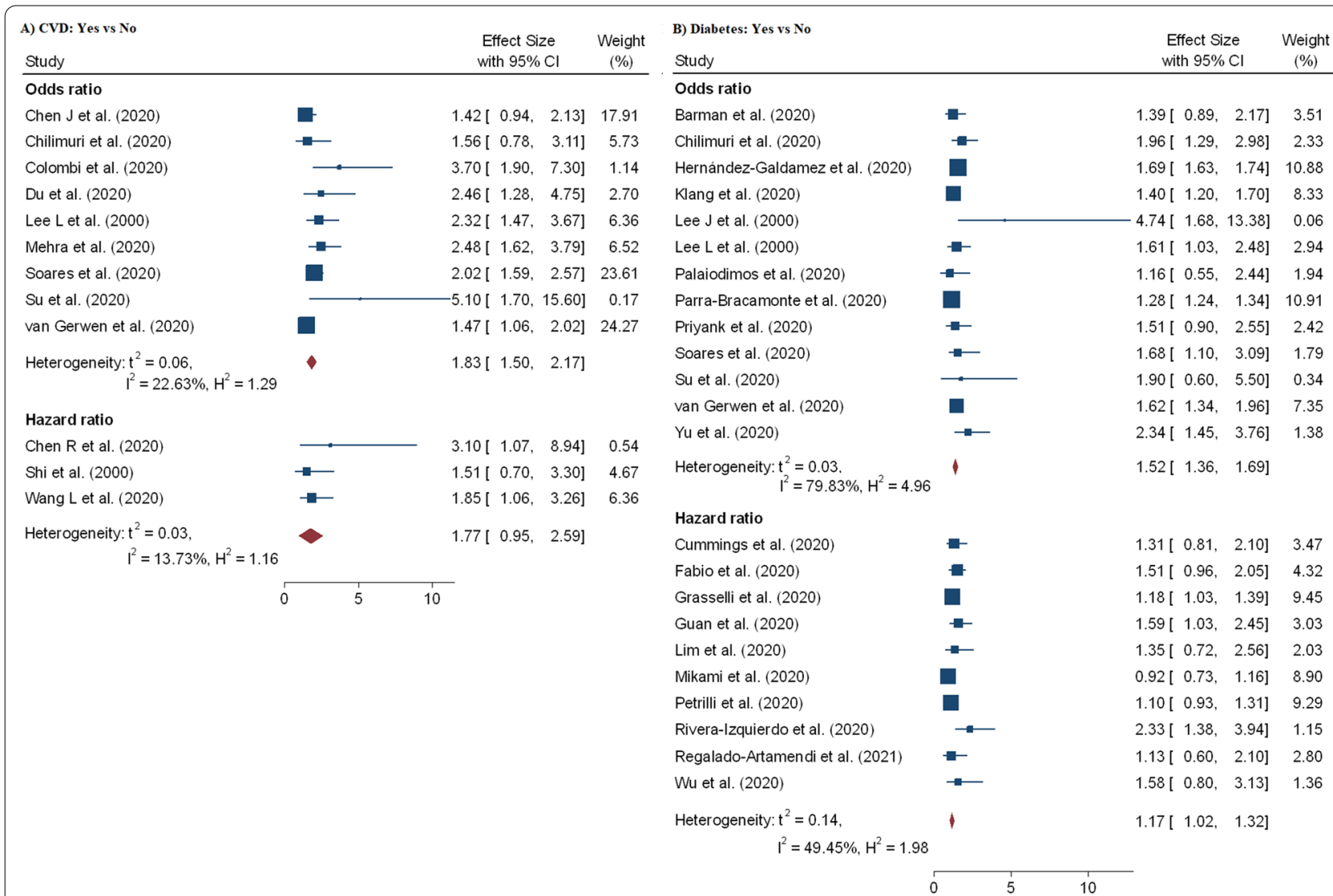

Fig. 6 Forest plot showing the estimate for the effects of CVDs and diabetes on COVID-19 mortality

STATA version 16, to estimate the pooled odds ratio and to investigate publication bias.

\section{Results}

\section{Search results}

We identified 150 publications through Google Scholar, Cochrane Library, Web of Sciences (WOS), EMBASE, Medline/PubMed, COVID-19 research database (WHO), COVID-19 open research dataset challenge, and Scopus database, of which, 14 studies that did not have numbers of hospital death, 31 reviews, 19 non-English, and 32 duplicates were excluded. Among the remaining 54 studies, twelve did not report cross-tabulation with ORs or HRs. Consequently, we got only 42 studies that satisfied all the eligibility criteria (see Fig. 1). Out of the 42 studies, thirty-nine provided adjusted hazard and odds ratios after multivariate adjustment for the covariates such as comorbidities, gender, smoking status, obesity, age, acute kidney injury, and D-dimer [17-52]. And the rest three studies provided crude hazard and odds ratios [53-55] (Table 1).
Demographic characteristics and geographical distribution Table 1 presents a systematic summary of all the selected studies $[2,6-9,12,15,18-21,25,26,28,30,35,40,42$, $45-47,50-52,55-68]$. All the 42 studies were published in the year 2020. All included studies were conducted in COVID-19 outbreak areas from December 2019 to August 2020. The studies reported a total of 423, 117 patients. Of these, 13 were performed in mainland China, 11 in USA, 2 in Spain, 2 in Mexico, 2 in Korea, 3 in Italy, 1 in France, 1 in Australia, 1 in Asia, 1 in Brazil, 1 in UK, 2 in Turkey and 2 mixed region. The sample size of enrolled patients ranged from 98 to 211,003 individuals. The proportions of male in the study samples ranged from 41.8 to $70.3 \%$. The average age of individuals included in the studies ranged from 48.9 to 77 years. (Table 1).

\section{Prevalence of COVID-19 mortality}

The mixed effect meta-analysis model results are presented in Fig. 2. From this plot, we can see that the mortality rate of coronaviruses among the included studies ranges from a minimum of 3.14 (95\% CI 2.34-4.12\%) [46] to a maximum of 61.51 (95\% CI 55.02-67.71\%) [19]. Of the total 423117 patients, 35020 died which resulted in 


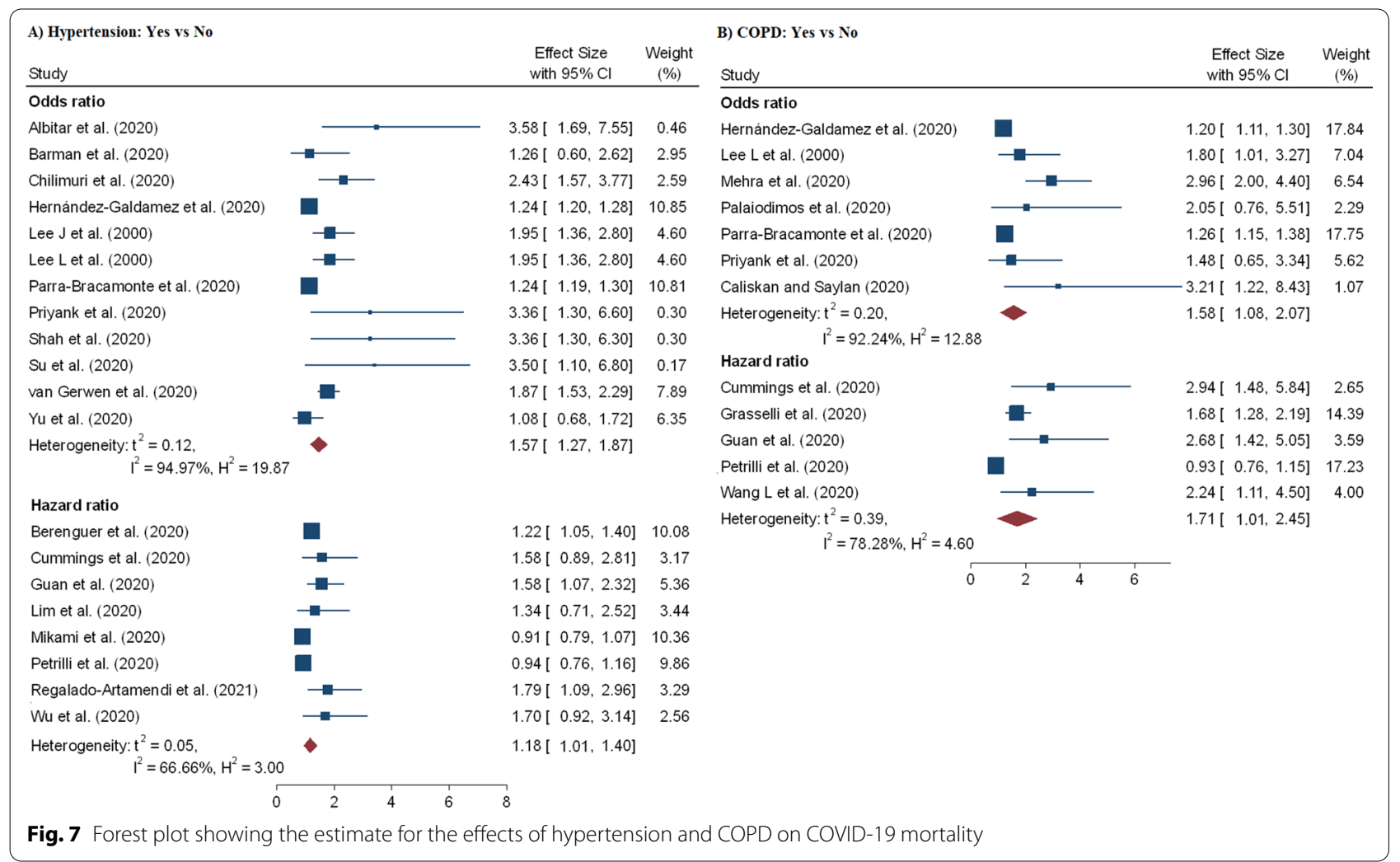

a weighted pooled overall mortality prevalence of $17.62 \%$ (95\% CI, 14.26-21.57\%). (Fig. 2).

\section{Mortality-related risk factors}

In the meta-analysis 32 effect sizes of the demographic characteristics were obtained from 37 studies [5, 9-12, $15,17,18,20-22,28,29,38,40,47-51,53,55,62,66,67$, 69, 70] (26 162 cases of death out of 203250 patients). Older age has shown increased risk of mortality due to coronavirus and the pooled OR and HR were 2.61 (95\% CI 1.75-3.47) and 1.31 (95\% CI 1.11-1.51), respectively (Table 2 and Fig. 3). Twenty-four studies evaluated the risk of COVID-19 mortality among male patients and showed a significantly higher risk and the pooled OR and HR were 1.45 (95\% CI 1.41-1.51) and 1.24 (95\% CI 1.07-1.41), respectively (Table 2 and Fig. 4). Coronavirus related risk of mortality was significantly associated with smoker patients when compared to non-smoker patients, (pOR $=1.42$; 95\% CI $=1.01-1.83$ ) (Fig. 5B). Furthermore, the combined 11 effect sizes from 11 studies $[2,10,21,22,24,28,31,40,44,51,56]$ revealed significant association between obesity and coronaviruses mortality $\quad(\mathrm{pOR}=1.34 ; \quad 95 \% \mathrm{CI}=1.17-1.52 ; \quad \mathrm{pHR}=1.50$; $95 \% \mathrm{CI}=1.26-1.75)$ (Fig. 5A).

A total of 60 effect sizes of comorbidities were extracted from 34 studies $[3,9,11,12,15,18,21-24,27$,
$28,31,39,40,44,48,50-52,54-57,67,69,71-73]$ with a total of 407, 638 patients and 32, 465 death. The association between diabetes and in-hospital mortality are displayed in Table 2 and Fig. 6B. We noted that mortality among hospitalized COVID-19 patients with diabetes was higher compared to the patients without diabetes $\mathrm{aOR}=1.52$ (95\% CI 1.36-1.69) and $\mathrm{aHR}=1.17$ (95\% CI 1.02-1.32). Likewise, risk of mortality among hospitalized COVID-19 patients is highly influenced by patients with COPD (pOR =1.58; 95\% CI 1.08-2.02; $\mathrm{pHR}=1.71$; 95\% CI 1.01-1.40) (Fig. 7B), hypertension (pOR = 1.57; 95\% CI 1.27-1.87; $\mathrm{pHR}=1.18 ; 95 \%$ CI $1.01-2.07)$ (Fig. 7A), CVD (pOR =1.83; 95\% CI 1.50-2.17) (Fig. 6A) and cancer ( $\mathrm{pHR}=1.33$; 95\% CI 1.09-1.56) (Fig. 8A).

In the meta-analysis of eight effect sizes from eight studies $[19,26,30,34,39,40,48,74]$, we noted that a significant positive association between acute kidney injury and COVID-19 mortality and the pooled OR and HR were 1.87 (95\% CI 1.48-2.26) and 2.21 (95\% CI 1.442.99), respectively (Fig. 9A). But acute cardiac injury association with COVID-19 fatality was not found to be significant $(\mathrm{pOR}=2.33 ; 95 \%$ CI $0.88-3.79 ; \mathrm{pHR}=1.89$; 95\% CI 0.75-3.02) (Fig. 8B). Furthermore, the combined effect sizes from six studies $[10,17,18,32,45$, 53] revealed a significant association between increase D-dimer and coronaviruses mortality $(\mathrm{pOR}=10.49$; 


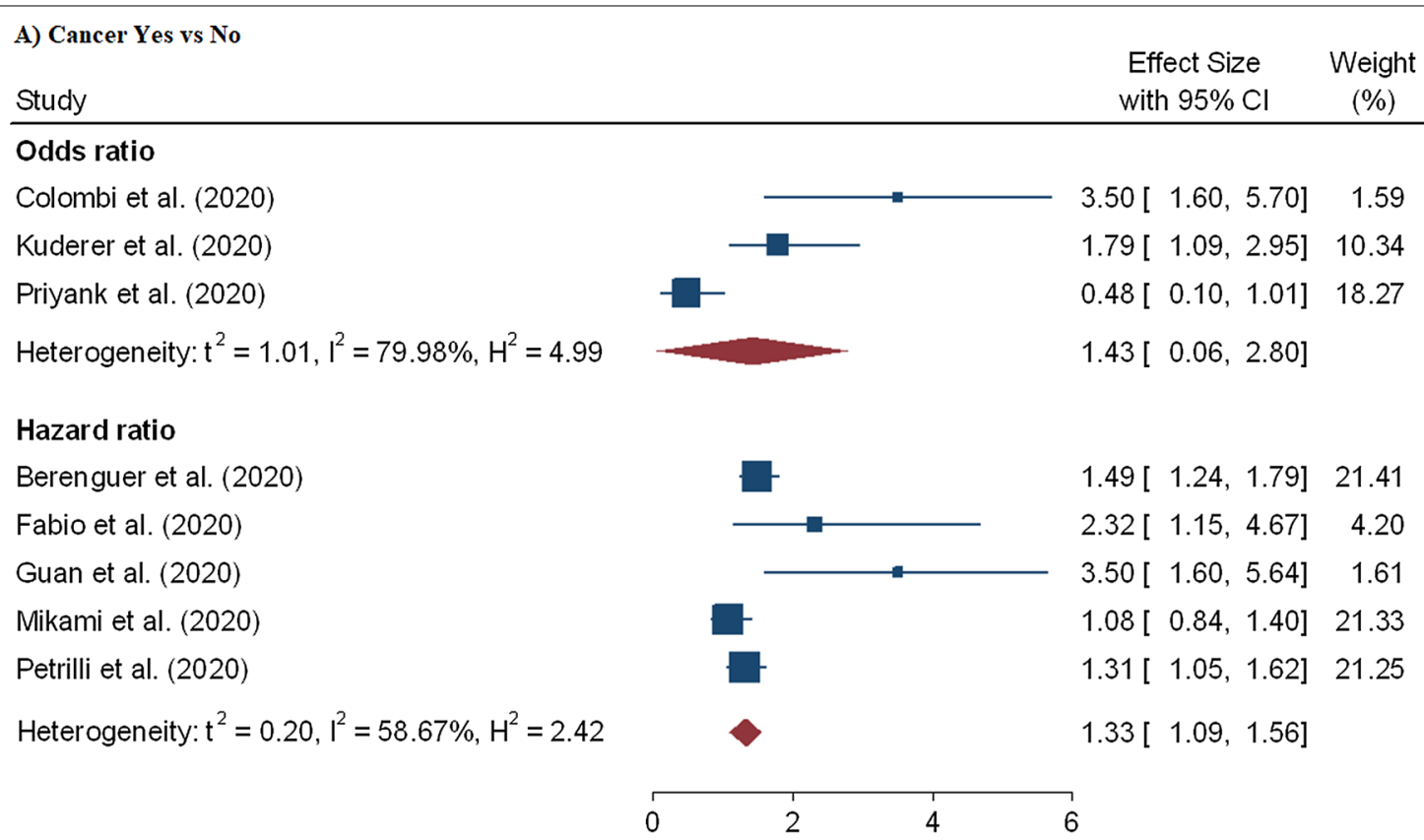

B) Cardiac injury: Yes vs No

Study

\section{Odds ratio}

Al-Salameh et al. (2020)

$2.01\left[\begin{array}{ll}1.13, & 3.58] \\ 19.71\end{array}\right.$

Barman et al. (2020)

Du et al. (2020)

Heterogeneity: $\mathrm{t}^{2}=0.25, \mathrm{I}^{2}=5.97 \%, \mathrm{H}^{2}=1.06$

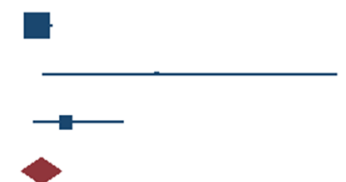

10.58 [ 2.42, 26.27] 0.16

$4.07[1.78,9.35] \quad 4.62$

$2.33[0.88,3.79]$

\section{Hazard ratio}

Cummings et al. (2020)

Li et al. (2020)

Shi et al. (2000)

Xu et al. (2020)

Heterogeneity: $\mathrm{t}^{2}=0.85, \mathrm{I}^{2}=76.57 \%, \mathrm{H}^{2}=4.27$

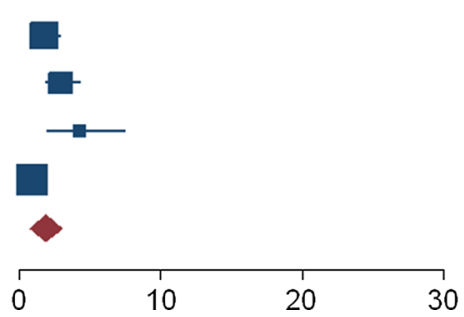

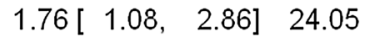

$2.92[1.80,4.76] 16.76$

$4.26[1.92,9.46] \quad 4.65$

$0.88[0.57,1.34] 30.06$

$1.89[0.75,3.02]$

Fig. 8 Forest plot showing the estimate for the effects of cancer and cardiac injury on COVID-19 mortality

95\% CI 1.80-19.18) and (pHR $=1.44 ; 95 \%$ CI 1.01-2.06)

(Fig. 9B).

\section{Quality Assessment}

The Newcastle-Ottawa score of the included studies was $7-9$, and the quality of the articles was evaluated as high (Table 3).
Sensitivity analysis, publication bias, and heterogeneity The $I^{2}$ statistics for gender, smoking status, obesity, CVDs, COPD, hypertension, cardiac injury, cancer, age, and D-dimer, had shown heterogeneities among the considered studies. From the sensitivity analysis, we noted that the overall estimates of comorbidities, gender, age, smoking status, obesity, acute kidney injury, and D-dimer on the fatal outcome of coronavirus, did not depend on a single study. Funnel plots were plotted for the included studies in the meta-analysis, which suggested that there 


\section{A) kidney injury: Yes vs No}

Study

Effect Size Weight

Odds ratio

Chen J et al. (2020)

Hernández-Galdamez et al. (2020)

Klang et al. (2020)

Parra-Bracamonte et al. (2020)

Priyank et al. (2020)

Heterogeneity: $\mathrm{t}^{2}=0.13, \mathrm{I}^{2}=86.53 \%, \mathrm{H}^{2}=7.43$

\section{Hazard ratio}

Lim et al. (2020)

Regalado-Artamendi et al. (2021)

Xu et al. (2020)

Heterogeneity: $\mathrm{t}^{2}=0.10, \mathrm{I}^{2}=42.43 \%, \mathrm{H}^{2}=1.74$
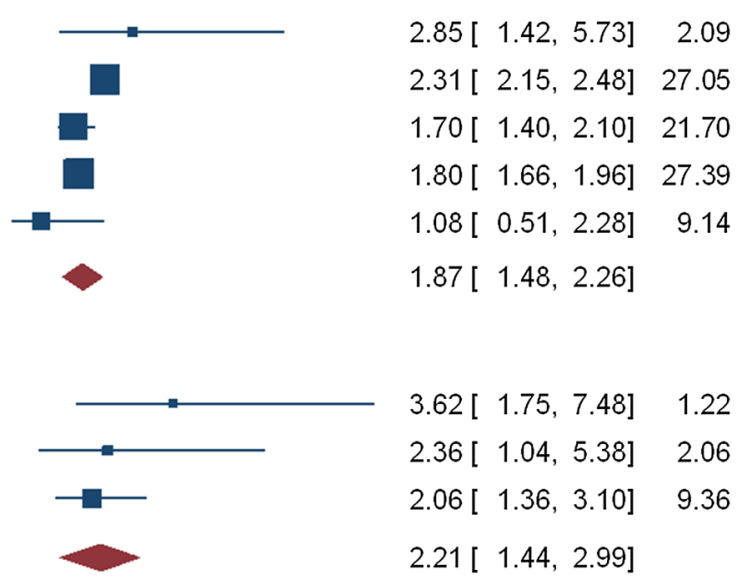

B) Increase D-dimmer

Study

Effect Size Weight

Odds ratio

Chilimuri et al. (2020)

Yao et al. (2020)

Zhou et al. (2020)

Heterogeneity: $\mathrm{t}^{2}=56.50, \mathrm{I}^{2}=96.14 \%, \mathrm{H}^{2}=25.92$

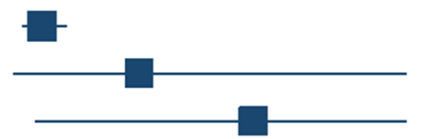

$3.16\left[\begin{array}{ll}1.75, & 5.73] \\ 12.48\end{array}\right.$

10.17 [ 1.10, 29.38] 11.77

18.42 [ 2.64, 29.39] 11.78

\section{Hazard ratio}

Chen L et al. (2020)

Cummings et al. (2020)

Mikami et al. (2020)

Regalado-Artamendi et al. (2021)

Wu et al. (2020)

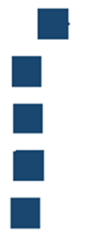

$10.49[1.80,19.18]$

Heterogeneity: $\mathrm{t}^{2}=0.37, \mathrm{I}^{2}=91.52 \%, \mathrm{H}^{2}=11.80$

Fig. 9 Forest plot showing the estimate for the effects of acute kidney injury, and D-dimer on COVID-19 mortality 


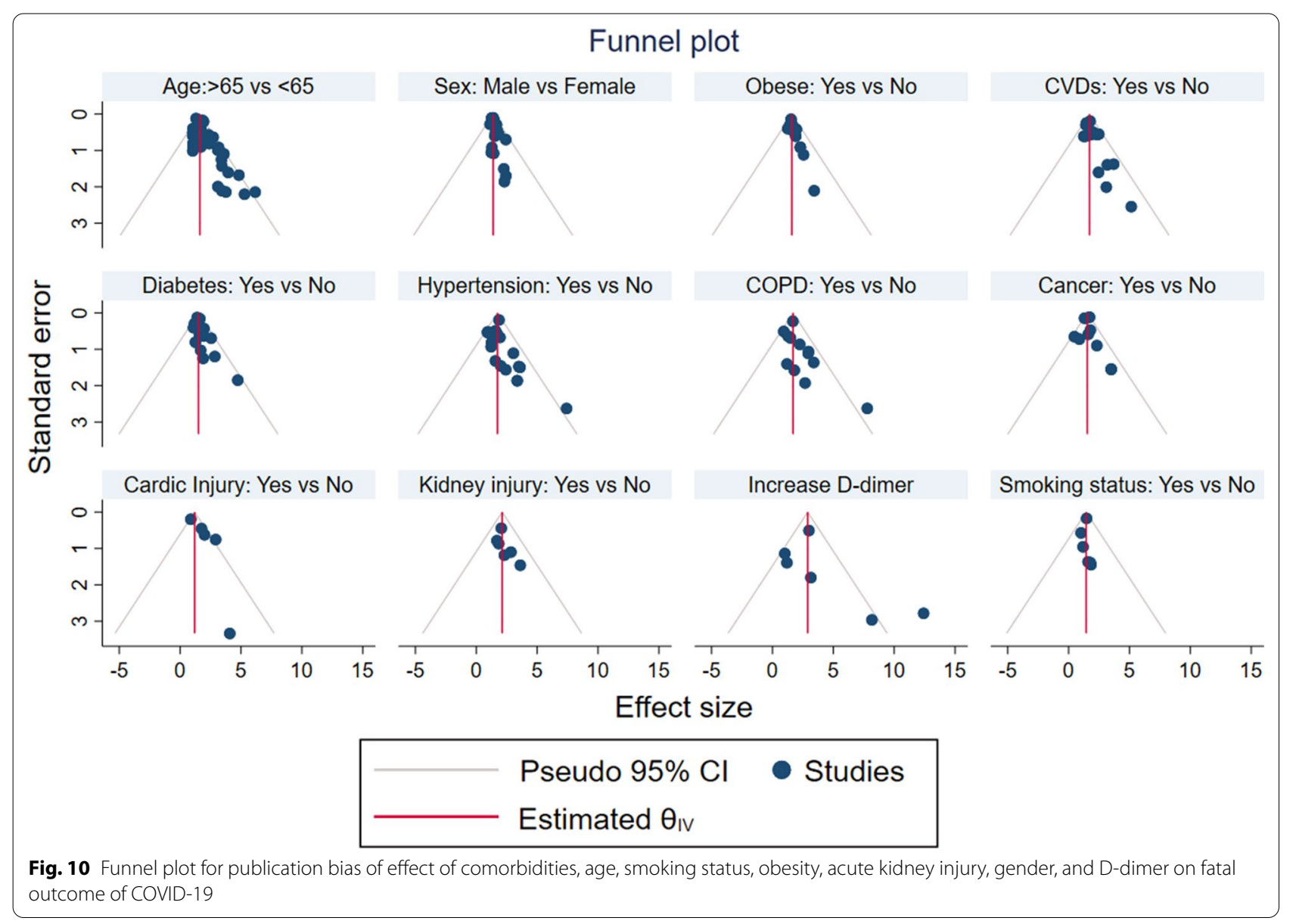




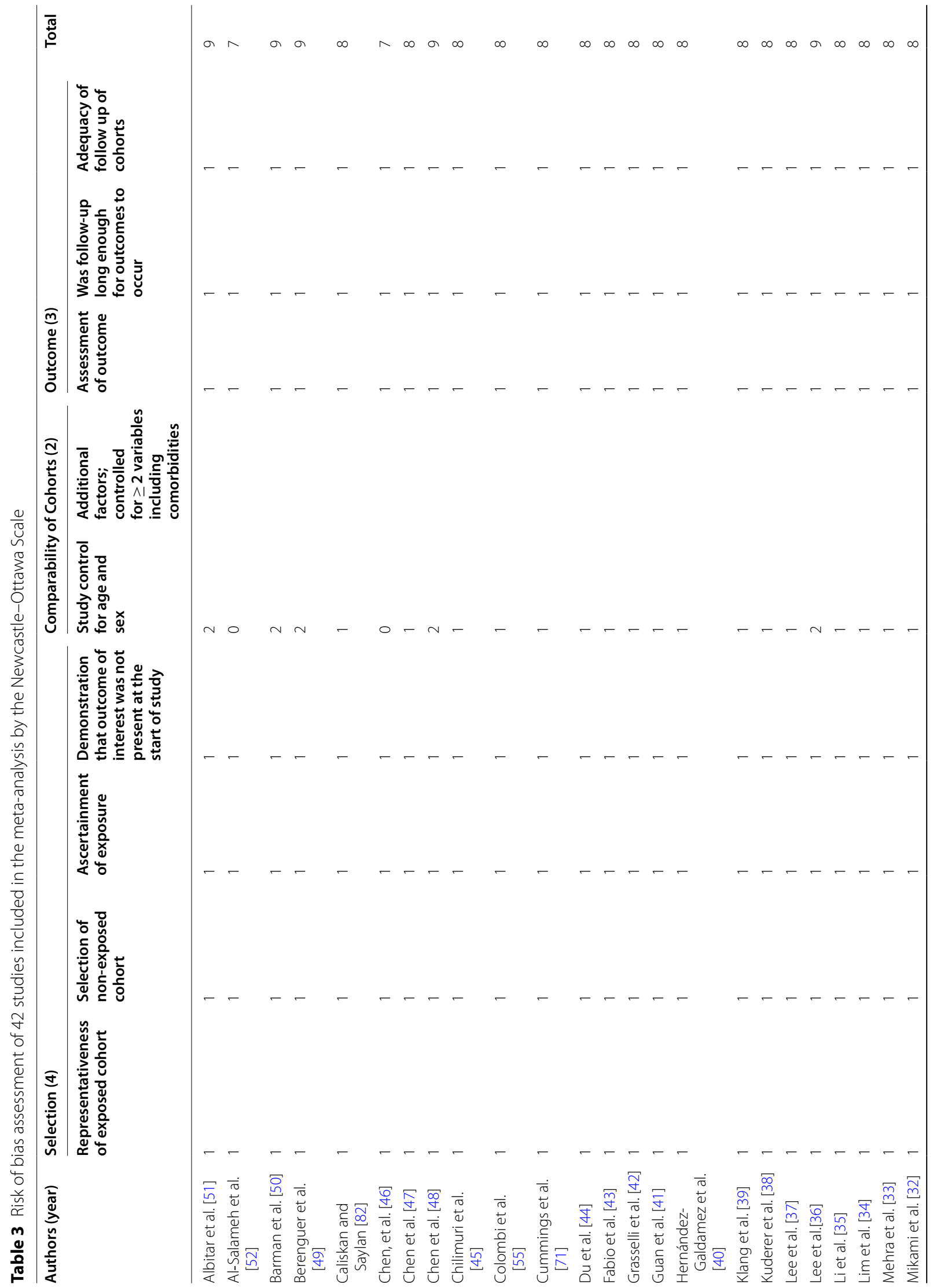




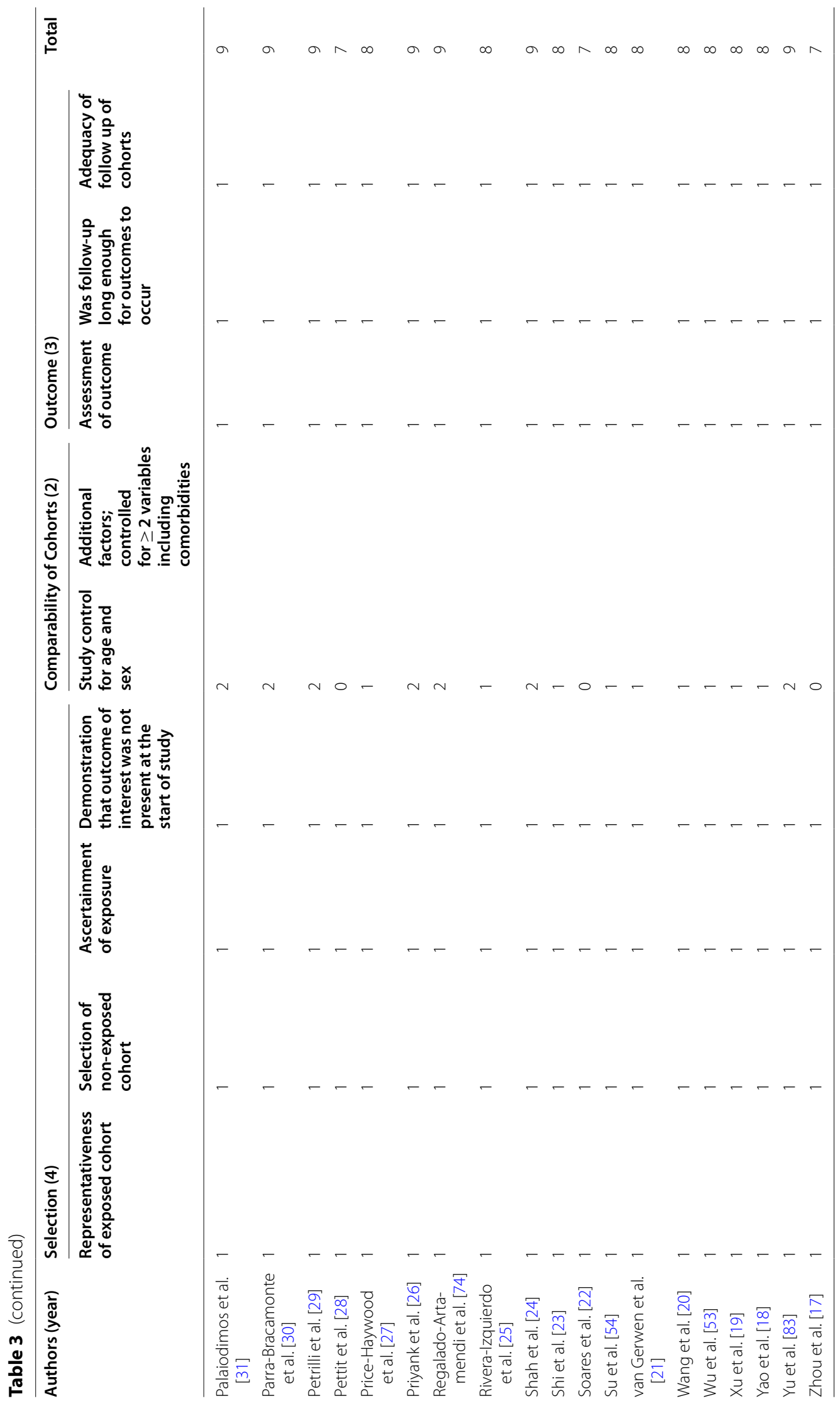


is no noticeable bias in the studies of our meta-analysis (Fig. 10). Besides, Begg's correlation rank and egger's regression failed to show significant publication bias (see Table 2).

\section{Discussion}

The meta-analysis of currently available regional and national reports of patients with coronavirus infection highlights the effect of complications, comorbidities, and demographic variables on mortality of coronavirus. These results have important clinical implications such as on the clinical management and specific preventive measures of coronavirus patients. Our study is by far the largest meta-analysis on COVID-19 fatality study in terms of size and coverage of complications, comorbidities, behavioural and demographic risk factors.

We found that smoking was significantly associated with the risk of mortality in coronavirus. Such a result was also reported [64] in a limited scale meta-analysis study. Accordingly, perhaps it is a high time step up effort to advocate the danger of smoking as well as an intervention to stop smoking to reduce the overall disease burden.

Reportedly old age was significantly associated with MERS-Cov [66] and SARS [68] mortality. Likewise, our finding showed a significant association of old age with coronavirus mortality. A plausible reason for this might be some age-related chronic medical conditions and/ or lower immunity level [57]. In addition, ageing affects CD4 + T cells, CD8 + T cells, B cells functions [75]. This age-related reduction in $\mathrm{T}$ cells and $\mathrm{B}$ cells clonal diversity is associated with impaired responses to viral infections such as influenza [76] and the excess production of type 2 cytokines could lead to prolonged pro-inflammatory immune responses and therefore perhaps contribute to poor outcomes [62].

Female with coronavirus have lower rates of hospitalization and mortality than male [77]. The results of our metaanalysis also showed that men seems to be a risk factor for COVID-19 mortality. Sex differences in both the adaptive and innate immune system have been reported previously and may account for the women advantage in coronavirus. Within the adaptive immune system, men have lower numbers of $\mathrm{CD} 8+\mathrm{T}$ cell [78], $\mathrm{CD} 4+\mathrm{T}$ cell [79] and decreased B cell production compared to women [79]. Moreover, since some important immune regulatory genes are located on the $\mathrm{X}$ chromosome, women patients might be advantaged due to a higher expression TLR7 [72]. Our systematic review result also confirmed that obesity was associated with death in coronavirus patients. Indeed previously limited scale meta-analysis study [70] had also shown the same findings.

From our systematic review, we found that diabetes, CVDs, COPD, hypertension, and acute kidney injury were the significant risk for COVID-19 mortality. These factors were also reported as the coronavirus risk factor by CDC and WHO. With regard to patients' COPD status and COVID-19 mortality association, studies [9] have argued that COPD patients with COVID-19 showed higher rates of hospitalization and mortality. This could be due to viral infections in COPD patients increase systemic inflammation with the slow recovery of reported symptoms [80]. In addition to the influence of coronavirus, COPD patients have various comorbidities, some of which are associated with an increased risk of hospitalization [69].

Diabetes also contributes to more severe COVID-19 and higher rates of mortality [81]. Our analysis also showed that mortality among hospitalized COVID-19 patients with diabetes was higher compared to the patients without diabetes. Thus, patients with diabetes and COVID-19 often need invasive ventilation care and need intensive care unit (ICU) due to their likelihood of developing Acute Respiratory Distress Syndrome (ARDS) [73]. Another two small systematic reviews, by $[67,73]$ also suggested that diabetes is a determinant of severity and mortality of COVID-19 patients.

Having a high D-dimer has shown a significantly increased odds of mortality. Previous study [59] had also shown that a high level of D-dimer increases severe infection and risk of mortality. In addition a study in China [17] have shown that rising D-dimer levels during the course of hospitalization are associated with the worst long-term outcomes. Therefore, using D-dimer levels as a surrogate marker for disease severity, especially, in coronavirus patients who cannot get dedicated imaging might be beneficial.

\section{Study limitations}

Although this systematic review presented pooled estimate from 42 studies across 13 geographical locations and may be considered broadly representative of the pandemic, our study has a few limitations. First, high heterogeneity could be found. This may relate to large variation in the sample size among studies (98-211,003 patients) and the study designs. Second, the literature on coronavirus continues to accumulate, new information and new papers published each day; therefore, our study cannot be considered as exhaustive. Finally, the sample size of some included studies was very small which might not recognize the possible factors that affects COVID-19 mortality.

\section{Conclusion}

Our study indicated a consistent and statistically significant effect of chronic comorbidities, complications, and demographic variables including acute kidney injury, COPD, diabetes, hypertension, CVDs, cancer, increased D-dimer, male gender, older age, current smoker, and 
obesity on the fatal outcome of COVID-19. Urgent public health interventions should be carefully tailored and implemented on those susceptible groups to reduce the risk of mortality in patients with COVID-19 and, then, the risk of major complications. An intensive and regular follow-up is required to detect early occurrences of clinical conditions.

\section{Abbreviations}

ARDS: Acute respiratory distress syndrome; COVID-19: Coronavirus infection pneumonia 2019; MERS: Middle East respiratory syndrome; pHR: Pooled hazard-ratio; pOR: Pooled odds-ratio; PRISMA-P: Preferred reporting Items for systematic reviews and meta-analyses protocols; SARS-CoV-2: Severe acute respiratory syndrome coronavirus 2.

\section{Authors' information}

ZGD is a postdoctoral student and TZ is senior professors at the University of KwaZulu-Natal.

\section{Acknowledgements}

We would like to thank the School of Mathematics, Statistics and Computer Science, University of KwaZulu-Natal, South Africa for providing their guidance and support.

\section{Authors' contributions}

ZGD designed the study, extracted and analyzed the data, and wrote the article. TZ contributed to the idea and design of this study, advised on analysis and revised the manuscript. Both authors searched the literature. Both authors read and approved the final manuscript.

\section{Funding}

No funding bodies played any role in the design, writing or decision to publish this manuscript.

\section{Availability of data and materials}

The dataset used and analyzed during the current study is available from the corresponding author on reasonable request.

\section{Declarations}

Ethics approval and consent to participate

Not applicable.

\section{Consent for publication}

Not applicable.

\section{Competing interests}

The authors declare that they have no competing interests.

\section{Author details}

${ }^{1}$ School of Mathematics, Statistics and Computer Science, University of KwaZulu-Natal, Durban, South Africa. ${ }^{2}$ College of Science, Bahir Dar University, Bahir Dar, Ethiopia.

Received: 10 June 2021 Accepted: 11 August 2021

Published online: 21 August 2021

\section{References}

1. Zhu N, Zhang D, Wang W, Li X, Yang B, Song J, Zhao X, Huang B, Shi W, Lu R. A novel coronavirus from patients with pneumonia in China, 2019.N. Engl. J. Med. 2020:382:727-733.

2. Peeri NC, Shrestha N, Rahman MS, Zaki R, Tan Z, Bibi S, Baghbanzadeh M, Aghamohammadi N, Zhang W, Haque U. The SARS, MERS and novel coronavirus (COVID-19) epidemics, the newest and biggest global health threats: what lessons have we learned? Int J Epidemiol. 2020;49:717-26.

3. Organization WH. Coronavirus disease (COVID-2019) situation reports. Geneva: World Health Organization; 2020. https://www.WHOInt/docs/ default-source/coronaviruse/situationreports/20200221-sitrep-32-covid. 2020;19. Accessed 15 Jan 2021.

4. ECDC. COVID-19 situation update worldwide, as of week 22021 updated January 2021. https://covid19-country-overviews.ecdc.europa.eu/.

5. Abate S, Checkol Y, Mantedafro B, Basu B, Ethiopia D. Prevalence and risk factors of mortality among hospitalized patients with COVID-19: a systematic review and Meta-analysis. Bull World Health Organ. 2020. https:// doi.org/10.2471/BLT.20.260737.

6. Arentz M, Yim E, Klaff L, Lokhandwala S, Riedo FX, Chong M, Lee M. Characteristics and outcomes of 21 critically ill patients with COVID-19 in Washington State. JAMA. 2020;323(16):1612-4.

7. Huang C, Wang Y, Li X, Ren L, Zhao J, Hu Y, Zhang L, Fan G, Xu J, Gu X. Clinical features of patients infected with 2019 novel coronavirus in Wuhan, China. The lancet. 2020;395(10223):497-506.

8. Wu Z, McGoogan JM. Characteristics of and important lessons from the coronavirus disease 2019 (COVID-19) outbreak in China: summary of a report of 72314 cases from the Chinese Center for Disease Control and Prevention. JAMA. 2020;323(13):1239-42.

9. Alqahtani JS, Oyelade T, Aldhahir AM, Alghamdi SM, Almehmadi M, Alqahtani AS, Quaderi S, Mandal S, Hurst JR. Prevalence, severity and mortality associated with COPD and smoking in patients with COVID-19: a rapid systematic review and meta-analysis. PLOS ONE. 2020;15(5):e0233147.

10. Chen M, Fan Y, Wu X, Zhang L, Guo T, Deng K, Cao J, Luo H, He T, Gong Y. Clinical characteristics and risk factors for fatal outcome in patients with 2019-coronavirus infected disease (COVID-19) in Wuhan, China. SSRN Electron J. 2020: https://doi.org/10.2139/ssrn.3546069.

11. Liu W, Tao Z-W, Wang L, Yuan M-L, Liu K, Zhou L, Wei S, Deng Y, Liu J, Liu H-G. Analysis of factors associated with disease outcomes in hospitalized patients with 2019 novel coronavirus disease. Chin Med J. 2020;133(9):1032-8.

12. Zhou F, Yu T, Du R, Fan G, Liu Y, Liu Z, Xiang J, Wang Y, Song B, Gu X. Clinical course and risk factors for mortality of adult inpatients with COVID-19 in Wuhan, China: a retrospective cohort study. Lancet. 2020;395:1054-62.

13. Hutton B, Salanti G, Caldwell DM, Chaimani A, Schmid CH, Cameron C, loannidis JP, Straus S, Thorlund K, Jansen JP. The PRISMA extension statement for reporting of systematic reviews incorporating network meta-analyses of health care interventions: checklist and explanations. Ann Internal Med. 2015;162(11):777-84.

14. Wells GA, Shea B, O'Connell D, Peterson J, Welch V, Losos M, Tugwell $P$ : Newcastle-Ottawa scale (NOS) for assessing the quality of nonrandomised studies in meta-analysis. 2009. http://www.ohri.ca/programs/ clinical_epidemiology/oxford.htm.

15. Higgins JP, Thompson SG, Deeks JJ, Altman DG. Measuring inconsistency in meta-analyses. BMJ. 2003;327(7414):557-60.

16. Peters JL, Sutton AJ, Jones DR, Abrams KR, Rushton L. Comparison of two methods to detect publication bias in meta-analysis. JAMA. 2006;295(6):676-80.

17. Zhou F, Yu T, Du R, Fan G, Liu Y, Liu Z, Xiang J, Wang Y, Song B, Gu X. Clinical course and risk factors for mortality of adult inpatients with COVID-19 in Wuhan, China: a retrospective cohort study. The Lancet. 2020;395:1054-62.

18. Yao Y, Cao J, Wang Q, Shi Q, Liu K, Luo Z, Chen X, Chen S, Yu K, Huang Z. D-dimer as a biomarker for disease severity and mortality in COVID-19 patients: a case control study. J Intensive Care. 2020;8(1):1-11.

19. Xu J, Yang X, Yang L, Zou X, Wang Y, Wu Y, Zhou T, Yuan Y, Qi H, Fu S. Clinical course and predictors of 60-day mortality in 239 critically ill patients with COVID-19: a multicenter retrospective study from Wuhan China. Crit Care. 2020;24(1):1-11.

20. Wang L, He W, Yu X, Hu D, Bao M, Liu H, Zhou J, Jiang H. Coronavirus disease 2019 in elderly patients: characteristics and prognostic factors based on 4-week follow-up. J Infect. 2020;80:639-645.

21. van Gerwen M, Alsen M, Little C, Barlow J, Genden E, Naymagon L, Tremblay D. Risk factors and outcomes of COVID-19 in New York City; a retrospective cohort study. J Med Virol. 2021;93(2):907-15. 
22. Soares RdCM, Mattos LR, Raposo LM. Risk factors for hospitalization and mortality due to COVID-19 in Espírito Santo State, Brazil. Am J Trop Med Hyg. 2020;103(3):1184-1190.

23. Shi S, Qin M, Shen B, Cai Y, Liu T, Yang F, Gong W, Liu X, Liang J, Zhao Q. Association of cardiac injury with mortality in hospitalized patients with COVID-19 in Wuhan, China. JAMA Cardiol. 2020; https://doi.org/10.1001/ jamacardio.2020.0950.

24. Shah P, Owens J, Franklin J, Mehta A, Heymann W, Sewell W, Hill J, Barfield K, Doshi R. Demographics, comorbidities and outcomes in hospitalized Covid-19 patients in rural southwest Georgia. Ann Med. 2020;52(7):354-60.

25. Rivera-Izquierdo M, del Carmen V-U, R-delAmo JL, Fernández-García MÁ, Martínez-Diz S, Tahery-Mahmoud A, Rodríguez-Camacho M, Gámiz-Molina AB, Barba-Gyengo N, Gámez-Baeza P. Sociodemographic, clinical and laboratory factors on admission associated with COVID-19 mortality in hospitalized patients: a retrospective observational study. PLoS ONE. 2020;15(6):e0235107.

26. Priyank $S$, Jack $O$, James $F$, Akshat $M$, William $H$, William $S$, Jennifer $H$, Krista B, Rajkumar D. Demographics, comorbidities, and outcomes in hospitalized Covid-19 patients in Rural Southwest Georgia. Ann Med. 2020;52(5):1791356.

27. Price-Haywood EG, Burton J, Fort D, Seoane L. Hospitalization and mortality among black patients and white patients with Covid-19. N Engl J Med. 2020;382:2534-43.

28. Pettit NN, MacKenzie EL, Ridgway J, Pursell K, Ash D, Patel B, Pho MT. Obesity is associated with increased risk for mortality among hospitalized patients with COVID-19. Obesity. 2020;28(10):1806-10.

29. Petrilli CM, Jones SA, Yang J, Rajagopalan H, O’Donnell L, Chernyak Y, Tobin KA, Cerfolio RJ, Francois F, Horwitz LI. Factors associated with hospital admission and critical illness among 5279 people with coronavirus disease 2019 in New York City: prospective cohort study. BMJ. 2020;369:m1966.

30. Parra-Bracamonte G, Lopez-Villalobos N, Parra-Bracamonte F. Clinical characteristics and risk factors for mortality of patients with COVID-19 in a large dataset from Mexico. Ann Epidemiol. 2020;52:93-8.

31. Palaiodimos L, Kokkinidis D, Li W, Karamanis D, Ognibene J, Arora S, Southern W, Mantzoros C. Severe obesity, increasing age and male sex are independently associated with worse in-hospital outcomes, and higher in-hospital mortality, in a cohort of patients with COVID-19 in the Bronx, New York. Metabolism. 2020;108:154262.

32. Mikami T, Miyashita H, Yamada T, Harrington M, Steinberg D, Dunn A, Siau E. Risk factors for mortality in patients with COVID-19 in New York City. J Gen Intern Med. 2021;36:17-26.

33. Mehra MR, Desai SS, Kuy S, Henry TD, Patel AN. Cardiovascular disease, drug therapy, and mortality in COVID-19. N Engl J Med. 2020;382(25):e102. https://doi.org/10.1056/NEJMoa2007621.

34. Lim J-H, Park S-H, Jeon Y, Cho J-H, Jung H-Y, Choi J-Y, Kim C-D, Lee Y-H, Seo H, Lee J. Fatal outcomes of COVID-19 in patients with severe acute kidney injury. J Clin Med. 2020;9(6):1718.

35. Li X, Xu S, Yu M, Wang K, Tao Y, Zhou Y, Shi J, Zhou M, Wu B, Yang Z. Risk factors for severity and mortality in adult COVID-19 inpatients in Wuhan. J Allergy Clin Immunol. 2020;146(1):110-8.

36. Lee LY, Cazier JB, Starkey T, Turnbull C, Team UCCMP, Kerr R, Middleton G. COVID-19 mortality in patients with cancer on chemotherapy or other anticancer treatments: a prospective cohort study. The Lancet. 2020;395(10241):1919-26.

37. Lee JY, Kim HA, Huh K, Hyun M, Rhee J-Y, Jang S, Kim J-Y, Peck KR, Chang $\mathrm{H}-\mathrm{H}$. Risk factors for mortality and respiratory support in elderly patients hospitalized with COVID-19 in Korea. J Korean Med Sci. 2020;35:e223.

38. Kuderer NM, Choueiri TK, Shah DP, Shyr Y, Rubinstein SM, Rivera DR, Shete S, Hsu C-Y, Desai A, de Lima Lopes Jr G. Clinical impact of COVID-19 on patients with cancer (CCC19): a cohort study. Lancet. 2020;395:1907-18.

39. Klang E, Kassim G, Soffer S, Freeman R, Levin MA, Reich DL. Morbid obesity as an independent risk factor for COVID-19 mortality in hospitalized patients younger than 50. Obesity. 2020;28(9):1595-9.

40. Hernández-Galdamez DR, González-Block MÁ, Romo-Dueñas DK, Lima-Morales R, Hernández-Vicente IA, Lumbreras-Guzmán M, MéndezHernández P. Increased risk of hospitalization and death in patients with COVID-19 and pre-existing noncommunicable diseases and modifiable risk factors. Arch Med Res. 2020;51 (7):683-9.
41. GGuan W-j, Liang W-h, Zhao Y, Liang H-r, Chen Z-s, Li Y-m, Liu X-q, Chen R-c, Tang C-I, Wang T. Comorbidity and its impact on 1590 patients with Covid-19 in China: a nationwide analysis. Eur Respir J. 2020;55(5):2000547.

42. Grasselli G, Greco M, Zanella A, Albano G, Antonelli M, Bellani G, Bonanomi E, Cabrini L, Carlesso E, Castelli G. Risk factors associated with mortality among patients with COVID-19 in Intensive Care Units in Lombardy, Italy. JAMA Intern Med. 2020;180(10):1345-55.

43. Fabio C, Antonella C, Patrizia R-Q, Annalisa R, Laura G, Caterina C, Andrea P, Alberto A, Carlo S, Eleonora B. Early predictors of clinical outcomes of COVID-19 outbreak in Milan, Italy. Clin Immunol. 2020;217:108509.

44. Du R-H, Liang L-R, Yang C-Q, Wang W, Cao T-Z, Li M, Guo G-Y, Du J, Zheng C-L, Zhu Q. Predictors of mortality for patients with COVID-19 pneumonia caused by SARS-CoV-2: a prospective cohort study. Eur Respir J. 2020;55(5):2000524.

45. Chilimuri S, Sun H, Alemam A, Mantri N, Shehi E, Tejada J, Yugay A, Nayudu SK. Predictors of mortality in adults admitted with COVID-19: retrospective cohort study from New York City. Western J Emerg Med. 2020:21(4):779.

46. Chen R, Liang W, Jiang M, Guan W, Zhan C, Wang T, Tang C, Sang L, Liu J, Ni Z. Risk factors of fatal outcome in hospitalized subjects with coronavirus disease 2019 from a nationwide analysis in China. Chest. 2020;158(1):97-105.

47. Chen L, Yu J, He W, Chen L, Yuan G, Dong F, Chen W, Cao Y, Yang J, Cai L. Risk factors for death in 1859 subjects with COVID-19. Leukemia. 2020;34(8):2173-83.

48. Chen J, Bai H, Liu J, Chen G, Liao Q, Yang J, Wu P, Wei J, Ma D, Chen G. Distinct clinical characteristics and risk factors for mortality in female COVID-19 inpatients: a sex-stratified large-scale cohort study in Wuhan, China. Clin Infect Dis. 2020;71(12):3188-95.

49. Berenguer J, Ryan P, Rodríguez-Baño J, Jarrín I, Carratalà J, Pachón J, Yllescas M, Arribas JR, Group C-SS. Characteristics and predictors of death among 4,035 consecutively hospitalized patients with COVID-19 in Spain. Clin Microbiol Infect. 2020;26(11):1525-36.

50. Barman HA, Atici A, Sahin I, Alici G, Tekin EA, Baycan ÖF, Ozturk F, Oflar E, Tugrul S, Baran Yavuz M. . Prognostic significance of cardiac injury in COVID-19 patients with and without coronary artery disease. Coronary Artery Dis. 2021:32(5):359-66.

51. Albitar O, Ballouze R, Ooi JP, Ghadzi SMS. Risk factors for mortality among COVID-19 patients. Diabetes Res Clin Practice. 2020;166:108293.

52. Al-Salameh A, Lanoix JP, Bennis Y, Andrejak C, Brochot E, Deschasse G, Dupont H, Goeb V, Jaureguy M, Lion S. Characteristics and outcomes of COVID-19 in hospitalized patients with and without diabetes. Diabetes/ Metab Res Rev. 2021;37(3):e3388.

53. Wu C, Chen X, Cai Y, Zhou X, Xu S, Huang H, Zhang L, Zhou X, Du C, Zhang $Y$. Risk factors associated with acute respiratory distress syndrome and death in patients with coronavirus disease 2019 pneumonia in Wuhan, China. JAMA Internal Med. 2020;180(7):934-43.

54. Su VYF, Yang Y-H, Yang K-Y, Chou K-T, Su W-J, Chen Y-M, Perng D-W, Chen T-J, Chen P-C. The risk of death in, novel coronavirus disease (COVID-19) in Hubei Province. Lancet. 2020. https://doi.org/10.2139/ssrn.3539655.

55. Colombi D, Bodini FC, Petrini M, Maffi G, Morelli N, Milanese G, Silva M, Sverzellati N, Michieletti E. Well-aerated lung on admitting chest CT to predict adverse outcome in COVID-19 pneumonia. Radiology. 2020;296(2):E86-96.

56. Zhang J-j, Dong X, Cao Y-y. Yuan Y-d, Yang Y-b, Yan Y-q, Akdis CA, Gao $Y$-d. Clinical characteristics of 140 patients infected with SARS-CoV-2 in Wuhan, China. Allergy. 2020;75(7):1730-41.

57. Wang K, Zuo P, Liu Y, Zhang M, Zhao X, Xie S, Zhang H, Chen X, Liu C. Clinical and laboratory predictors of in-hospital mortality in 305 patients with COVID-19: a Cohort Study in Wuhan, China. China (2/24/2020). 2020;71(16):2079-88.

58. Singh AK, Gupta R, Ghosh A, Misra A. Diabetes in COVID-19: Prevalence, pathophysiology, prognosis and practical considerations. Diabetes Metab Syndr: Clin Res Rev. 2020;14(4):303-10.

59. Shah S, Shah K, Patel SB, Patel FS, Osman M, Velagapudi P, Turagam MK, Lakkireddy D, Garg J. Elevated D-dimer levels are associated with increased risk of mortality in COVID-19: a systematic review and metaanalysis. Cardiol Rev. 2020;28(6):295-302.

60. Seys LJ, Widagdo W, Verhamme FM, Kleinjan A, Janssens W, Joos GF, Bracke KR, Haagmans BL, Brusselle GG. DPP4, the Middle East respiratory syndrome coronavirus receptor, is upregulated in lungs of smokers 
and chronic obstructive pulmonary disease patients. Clin Infect Dis. 2018;66(1):45-53.

61. Rojas-Osornio SA, Cruz-Hernández TR, Drago-Serrano ME, Campos-Rodríguez R. Immunity to influenza: impact of obesity. Obes Res Clin Pract. 2019;13(5):419-29.

62. Opal SM, Girard TD, Ely EW. The immunopathogenesis of sepsis in elderly patients. Clin Infect Dis. 2005;41(Supplement_7):S504-12

63. Kumar A, Arora A, Sharma P, Anikhindi SA, Bansal N, Singla V, Khare S, Srivastava A. Is diabetes mellitus associated with mortality and severity of COVID-19? A meta-analysis. Diab Metab Syndr. 2020;14(4):535-545.

64. Karanasos A, Aznaouridis K, Latsios G, Synetos A, Plitaria S, Tousoulis D, Toutouzas K. Impact of smoking status on disease severity and mortality of hospitalized patients with COVID-19 infection: a systematic review and meta-analysis. Nicotine Tobacco Res. 2020;22(9):1657-9.

65. Jaillon S, Berthenet K, Garlanda C. Sexual dimorphism in innate immunity. Clin Rev Allergy Immunol. 2019;56(3):308-21.

66. Hong K-H, Choi J-P, Hong S-H, Lee J, Kwon J-S, Kim S-M, Park SY, Rhee J-Y, Kim B-N, Choi HJ. Predictors of mortality in Middle East respiratory syndrome (MERS). Thorax. 2018;73(3):286-9.

67. Fadini G, Morieri M, Longato E, Avogaro A. Prevalence and impact of diabetes among people infected with SARS-CoV-2. J Endocrinol Investig. 2020;43(6):867-9

68. Choi KW, Chau TN, Tsang O, Tso E, Chiu MC, Tong WL, Lee PO, Ng TK, Ng WF, Lee KC. Outcomes and prognostic factors in 267 patients with severe acute respiratory syndrome in Hong Kong. Ann Internal Med. 2003;139(9):715-23.

69. Hurst JR, Skolnik N, Hansen GJ, Anzueto A, Donaldson GC, Dransfield MT, Varghese P. Understanding the impact of chronic obstructive pulmonary disease exacerbations on patient health and quality of life. Eur J Internal Med. 2020;73:1-6.

70. Tamara A, Tahapary DL. Obesity as a predictor for a poor prognosis of COVID-19: A systematic review. Diabetes Metab Syndr. 2020;14(4):655-659.

71. Cummings MJ, Baldwin MR, Abrams D, Jacobson SD, Meyer BJ, Balough EM, Aaron JG, Claassen J, Rabbani LE, Hastie J. Epidemiology, clinical course, and outcomes of critically ill adults with COVID-19 in New York City: a prospective cohort study. Lancet. 2020;395(10239):1763-70.

72. Parohan M, Yaghoubi S, Seraji A, Javanbakht MH, Sarraf P, Djalali M. Risk factors for mortality in patients with Coronavirus disease 2019 (COVID-19) infection: a systematic review and meta-analysis of observational studies. The Aging Male. 2020;23(5):1416-24.
73. Wang B, Li R, Lu Z, Huang Y. Does comorbidity increase the risk of patients with COVID-19: evidence from meta-analysis. Aging (Albany NY). 2020;12(7):6049.

74. Regalado-Artamendi I, Jiménez-Ubieto A, Hernández-Rivas JÁ, Navarro B, Núñez L, Alaez C, Córdoba R, Peñalver FJ, Cannata J, Estival P. Risk factors and mortality of COVID-19 in patients with lymphoma: a multicenter study. Hemasphere. 2021:5(3):e538.

75. Goronzy JJ, Weyand CM. Successful and maladaptive T cell aging. Immunity. 2017;46(3):364-78.

76. Pourgheysari B, Khan N, Best D, Bruton R, Nayak L, Moss PA. The cytomegalovirus-specific CD4+ T-cell response expands with age and markedly alters the CD4+ T-cell repertoire. J Virol. 2007;81(14):7759-65.

77. Scully EP, Haverfield J, Ursin RL, Tannenbaum C, Klein SL. Considering how biological sex impacts immune responses and COVID-19 outcomes. Nat Rev Immunol. 2020;20:442-7.

78. Hewagama A, Patel D, Yarlagadda S, Strickland FM, Richardson BC Stronger inflammatory/cytotoxic T-cell response in women identified by microarray analysis. Genes Immun. 2009;10(5):509-16.

79. Abdullah M, Chai P-S, Chong M-Y, Tohit ERM, Ramasamy R, Pei CP, Vidyadaran S. Gender effect on in vitro lymphocyte subset levels of healthy individuals. Cell Immunol. 2012;272(2):214-9.

80. Williams NP, Ostridge K, Devaster J-M, Kim V, Coombs NA, Bourne S, Clarke SC, Harden S, Abbas A, Aris E. Impact of radiologically stratified exacerbations: insights into pneumonia aetiology in COPD. Respir Res. 2018;19(1):143

81. Fang L, Karakiulakis G, Roth M. Are patients with hypertension and diabetes mellitus at increased risk for COVID-19 infection? The Lancet Respir Med. 2020;8(4):e21.

82. Caliskan T, Saylan B. Smoking and comorbidities are associated with COVID-19 severity and mortality in 565 patients treated in Turkey: a retrospective observational study. Rev Assoc Med Bras. 2020;66(12):1679-84.

83. Yu C, Lei Q, Li W, Wang X, Liu W, Fan X, Li W. Clinical characteristics, associated factors, and predicting COVID-19 mortality risk: a retrospective study in Wuhan, China. Am J Prev Med. 2020;59(2):168-75.

\section{Publisher's Note}

Springer Nature remains neutral with regard to jurisdictional claims in published maps and institutional affiliations.
Ready to submit your research? Choose BMC and benefit from:

- fast, convenient online submission

- thorough peer review by experienced researchers in your field

- rapid publication on acceptance

- support for research data, including large and complex data types

- gold Open Access which fosters wider collaboration and increased citations

- maximum visibility for your research: over $100 \mathrm{M}$ website views per year

At BMC, research is always in progress.

Learn more biomedcentral.com/submissions 